\title{
Glycosylphosphatidyl Inositol-anchored Proteins and fyn Kinase Assemble in Noncaveolar Plasma Membrane Microdomains Defined by Reggie-1 and -2
}

\author{
Claudia A.O. Stuermer, ${ }^{*}$ Dirk M. Lang, ${ }^{+}$Friederike Kirsch, Marianne \\ Wiechers, Sören-Oliver Deininger, and Helmut Plattner
}

\author{
Department of Biology, University of Konstanz, 78467 Konstanz, Germany
}

Submitted February 12, 2001; Revised July 5, 2001; Accepted July 30, 2001

Monitoring Editor: Monty Krieger

\begin{abstract}
Using confocal laser scanning and double immunogold electron microscopy, we demonstrate that reggie- 1 and -2 are colocalized in $\leq 0.1-\mu \mathrm{m}$ plasma membrane microdomains of neurons and astrocytes. In astrocytes, reggie- 1 and -2 do not occur in caveolae but clearly outside these structures. Microscopy and coimmunoprecipitation show that reggie- 1 and -2 are associated with fyn kinase and with the glycosylphosphatidyl inositol-anchored proteins Thy-1 and F3 that, when activated by antibody cross-linking, selectively copatch with reggie. Jurkat cells, after crosslinking of Thy-1 or GM1 (with the use of cholera toxin), exhibit substantial colocalization of reggie-1 and -2 with Thy-1, GM1, the T-cell receptor complex and fyn. This, and the accumulation of reggie proteins in detergent-resistant membrane fractions containing F3, Thy-1, and fyn imparts to reggie-1 and -2 properties of raft-associated proteins. It also suggests that reggie- 1 and -2 participate in the formation of signal transduction centers. In addition, we find reggie- 1 and -2 in endolysosomes. In Jurkat cells, reggie-1 and -2 together with fyn and Thy-1 increase in endolysosomes concurrent with a decrease at the plasma membrane. Thus, reggie- 1 and -2 define raft-related microdomain signaling centers in neurons and $\mathrm{T}$ cells, and the protein complex involved in signaling becomes subject to degradation.
\end{abstract}

\section{INTRODUCTION}

Plasma membrane microdomains or lipid rafts (Simons and Ikonen, 1997) allow the spatial concentration of specific sets of proteins and thereby increase the efficiency and specificity of signal transduction cascades (Brown and London, 1998; Harder et al., 1998; Brückner et al., 2000; Simons and Toomre, 2000). Glycosylphosphatidyl inositol (GPI)-anchored cell surface proteins that have no direct access to intracellular aspects of the cell cluster in such

\footnotetext{
* Corresponding author. E-mail address: claudia.stuermer@unikonstanz.de.

+ Present address: Dr. Dirk M. Lang, Department of Human Biology, Faculty of Health Sciences, University of Cape Town, Observatory 7925, Cape Town, Republic of South Africa. E-mail address: dlang@cormack.uct.ac.za.

Abbreviations used: $\mathrm{AB}$, antibody; $\mathrm{CAM}$, cell adhesion molecule; CTX, cholera toxin; DRM, detergent resistant membrane fraction; DRG, dorsal root ganglion; EM, electron microscope; ESA, epidermal surface antigen; GPI, glycosylphosphatidyl inositol; HRP, horseradish peroxidase; IG, immunogold; LIMP-2, lysosomal integral membrane protein-2; LSM, confocal laser scanning microscope; $\mathrm{mAB}$, monoclonal antibody; $\mathrm{pA}$, protein $\mathrm{A} ; \mathrm{pAB}$, polyclonal antibody; $\mathrm{PC} 12$, phaeochromocytoma; RT, room temperature.
}

microdomains when they become activated by the binding of ligands or when ligand binding is mimicked by antibody-induced cross-linking (Friedrichson and Kurzchalia, 1998; Harder et al., 1998). This leads to the formation of microscopically visible "clustered rafts" and promotes protein interactions and signaling, often through src family tyrosine kinases (and possibly other proteins involved in signal transduction) (Brown and London, 1998; Varma and Mayor, 1998; Simons and Toomre, 2000).

Raft-associated proteins are enriched in nonionic detergent (Triton X-100)-resistant membrane (DRM) complexes. Depending on the tissue and cell types, such DRMs may contain 21-25-kDa caveolin proteins (Harder and Simons, 1997). Caveolin-1 is required for the formation of $80 \times$ 100-nm flask-shaped invaginations, i.e., caveolae (Parton, 1996), which have been implicated in transcytosis, endocytosis, cholesterol transport, and signal transduction (reviewed in Simons and Toomre, 2000). They are also thought to be signaling centers for activated GPI-linked proteins (Lisanti et al., 1994). Caveolae are abundant in glial cells but absent from neurons and lymphocytes (Fra et al., 1994; Gorodinsky and Harris, 1995; Schnitzer et al., 1995; Lang et al., 1998; Simons and Toomre, 2000), which nevertheless signal through rafts. 
We became interested in rafts/microdomains when we identified two proteins of $47 \mathrm{kDa}$ in axon-regenerating neurons. We named these proteins reggie-1 and reggie-2 (Schulte et al., 1997). The same proteins were independently identified and named flotillin-2 and flotillin-1 (Bickel et al., 1997; Volonté et al., 1999). They were regarded as constituents of caveolae.

There is agreement on the fact that they are contained in DRMs (Bickel et al., 1997; Lang et al., 1998). Our analysis of astrocytes and neurons suggested that they do not occur in caveolae (Lang et al., 1998). With specific antibodies, we showed that reggie-1 and reggie- 2 are colocalized at the inner aspect of the plasma membrane in glial cells and neurons and their axons where they exhibit a punctate distribution indicative of microdomains (Lang et al., 1998). In neurons, reggie-1 and -2 define microdomains where specific GPI-linked proteins, after activation by antibody crosslinking, preferentially assemble (Lang et al., 1998).

That was established by conventional immunofluorescence light microscopy with its known limitation of spatial resolution (Varma and Mayor, 1998). Here, we used confocal laser scanning microscopy (LSM), which allows the analysis of optical sections with improved resolution in the $z$-axis (Nagorni and Hell, 1998) and has the advantage that large areas of the cells can be scanned. We also used electron microscopy (EM) combined with double immunogold (IG) labeling, and we demonstrate that the proteins of interest are colocalized within the resolution of the IG method on EM sections. Moreover, our present IG EM analysis on astrocytes demonstrates that reggie- 1 and -2 do not occur in caveolae, but in microdomains outside these structures. Because F3 and Thy-1 induce signaling cascades that involve the src family tyrosine kinase fyn (Weiss, 1993; Olive et al., 1995; Krämer et al., 1997, 1999; Ilangumaran et al., 1999), we combined microscopic analysis and coimmunoprecipitation to show that reggie- 1 and -2 proteins are assembled in a complex that contains activated GPI-linked cell adhesion molecules (CAMs) and includes fyn. It is well established that cross-linking of the raft-associated ganglioside GM1 by cholera toxin (CTX), and activation of Thy-1 in T lymphocytes leads to clustering of GM1, Thy-1, the T-cell receptor complex (Fra et al., 1994; Harder et al., 1998; Janes et al., 1999) and src tyrosine kinases, including fyn (Thomas and Samelson, 1992; Brown, 1993; Ilangumaran et al., 1999; Simons and Toomre, 2000), in a process known as capping (Harder et al., 1998; Hooper, 1999; Janes et al., 1999). Because this wellstudied system demonstrates the induction of signaling cascades in response to lateral clustering of a GPI-linked protein and coalescing raft microdomains (Brown and London, 1998; Hooper, 1999), we included Jurkat T-lymphoma cells in our present investigation. During capping in $\mathrm{T}$ lymphocytes, reggie- 1 and -2 associate with the activated T-cell receptor complex, with clustered Thy-1, CTX-mediated clusters of GM1, antiphosphotyrosine immunoreactivity, and fyn. Reggie-1 and -2 also occur in cytoplasmic vacuoles, which we identify as endolysosomes. In Jurkat cells, the endolysosomes contain Thy-1 and fyn in conjunction with reggie- 1 and -2 . Taken together, these results suggest that reggie- 1 and -2 define plasma membrane microdomains, distinct from caveolae, but that they also participate in protein complexes at specific sites where signaling across the plasma membrane is taking place, and that they are targeted to endolysosomes for inactivation.

\section{MATERIALS AND METHODS}

\section{Cell Culture}

Phaeochromocytoma (PC12) cells (kindly provided by M. Schwab, University of Zurich, Switzerland) were grown on a polylysine substrate in DME (Life Technologies, Karlsruhe, Germany) with $2 \%$ fetal calf serum (FCS) and $100 \mathrm{ng} / \mathrm{ml}$ nerve growth factor (Sigma, Deisenhofen, Germany) for at least $7 \mathrm{~d}$. Jurkat cells were grown in DME containing 10\% FCS. Astrocytes, prepared from postnatal day (P) 1-3 rat brains as described (Lang et al., 1996), were grown in DME with $10 \%$ FCS in polylysine-coated culture flasks $\left(75 \mathrm{~cm}^{2}\right)$. Astrocytes were removed from the flasks by incubation with $0.01 \%$ trypsin (Sigma) and $0.02 \%$ EDTA in calcium- and magnesium-free Hanks' balanced salt solution for $5 \mathrm{~min}$ and replated on polylysinecoated coverslips in DME containing 10\% FCS. Dorsal root ganglion (DRG) neurons from P1-3 rats were obtained by mechanical trituration of tissue fragments and separation of tissue aggregates from single cells as described (Lang et al., 1996). Cells were taken up in modified L15-medium (Mains and Patterson, 1973) with 5\% FCS and $100 \mathrm{ng} / \mathrm{ml}$ nerve growth factor (Sigma) and grown overnight $\left(\sim 10^{3}\right.$ cells $\left./ \mathrm{cm}^{2}\right)$. For immunohistochemistry and LSM analysis astrocytes, PC12 cells and DRG neurons were grown on glass coverslips coated with polylysine/laminin. Jurkat cells were centrifuged onto polylysine-coated coverslips at $900 \mathrm{rpm}$ for $5 \mathrm{~min}$ at $4^{\circ} \mathrm{C}$.

\section{Antibodies}

Recombinant goldfish reggie-2 protein was isolated from transformed Escherichia coli (Schulte et al., 1997) and used to immunize rabbits (chinchilla bastard) as well as BALB/c mice according to standard protocols. Hybridoma cells were produced under standard culture conditions, and supernatants screened for reggie-2specific staining in rat astrocytes. For purification of IgG fractions, rabbit antisera were passed over a protein A (pA) column. To eliminate cross-reactivity with reggie-1, the $\operatorname{Ig} G$ fractions were preadsorbed with recombinant reggie-1 protein bound to N-hydroxy succinimide sepharose (Sigma). Specificity of rabbit IgG fractions $(\mathrm{pAB})$ and monoclonal antibodies $(\mathrm{mABs})$ for reggie-2 was tested on recombinant reggie- 1 and -2 , in immunoblots with the relevant cells/tissue and in immunoprecipitation experiments.

Primary antibodies were anti-ESA (Transduction Laboratories, Lexington, KY) recognizing human, rat, and goldfish reggie-1 (Schroeder et al., 1994; Lang et al., 1998), anti-reggie-2 pAB and mAB, anti-Thy-1 mABs (rat, OX-7; Linaris, Wertheim-Bettingen, Germany, and human AF9; BioTrend, Köln, Germany) as well as goat anti-Thy-1 pAB (human; Santa Cruz Biotechnology, Santa Cruz, CA), anti-CD3 (clone UCHT-1; Biotrend, Köln, Germany), and anti-phosphotyrosine mABs (clone PY-20; Santa Cruz Biotechnology), pAB anti-caveolin-1 (Transduction Laboratories and Santa Cruz Biotechnology, respectively) and mAB anti-caveolin-1 (Transduction Laboratories), anti-F3 pAB (kindly provided by G. Gennarini, Bari, Italy), anti-fyn pAB and mAB (Upstate Biotechnology, Lake Placid, NY), anti-lysosomal integral membrane protein-2 (limp-2) pAB and mAB (Vega et al., 1991; kind gift of S. Hoening, University of Goettingen, Germany), anti-58-kDa Golgi protein (Sigma), anti-HRP (Sigma), and anti-CTX pABs (Sigma). The specificity of the antibodies was verified in immunoblots with proteins from rat brain, rat DRGs, astrocytes, PC12 cells, and the human Tlymphocytic Jurkat cell line.

\section{Immunoprecipitation Experiments}

Two methods were used: 1) Rat brain tissue, DRGs, and pelleted cells were homogenized on ice in modified radioimmuno precipitation-assay buffer (Sambrook et al., 1989) containing 1\% NP-40 (Roche Molecular Biochemicals), 0.5\% sodium deoxycholate (Sig- 
ma), and $0.2 \%$ SDS (Sigma) as well as a protease inhibitor cocktail (Complete Mini; Roche Molecular Biochemicals, Mannheim, Germany). The homogenates were incubated on ice and insoluble fractions removed by centrifugation. Immunoprecipitating pABs (antireggie-2, anti-caveolin-1, anti-F3, anti-Thy-1, or anti-fyn) and $\mathrm{mABs}$ (ESA/anti-reggie-1, anti-reggie-2, anti-caveolin-1, OX-7/anti-ratThy-1, AF9/anti-human-Thy-1) were incubated with the extracts at concentrations of $\sim 1-10 \mu \mathrm{g} / \mathrm{ml}$ for at least $2 \mathrm{~h}$ at $4^{\circ} \mathrm{C}$. $\mathrm{mAB}$ and pAB-antigen complexes were precipitated with pA-Sepharose (50 $\mu \mathrm{l} / \mathrm{ml}$ extract; Amersham Pharmacia Biotech, Freiburg, Germany) overnight at $4^{\circ} \mathrm{C}$. The precipitates were washed at least three times in radioimmuno precipitation-assay buffer and processed for immunoblot analysis. 2) Rat brain, astrocytes, PC12, and Jurkat cells were homogenized on ice in Tris-buffered saline (TBS) buffer (50 mM Tris, $150 \mathrm{mM} \mathrm{NaCl}, 2 \mathrm{mM}$ EDTA, pH 7.4) containing 1\% NP-40 (Roche Molecular Biochemicals) and protease inhibitor cocktail. The homogenates were incubated on ice and insoluble fractions removed by centrifugation for $10 \mathrm{~min}$ at $4^{\circ} \mathrm{C}, 14,000 \mathrm{rpm}$ in a microcentrifuge. a) Cell homogenate $(500 \mu \mathrm{l})$ was incubated with $20 \mu \mathrm{l}$ of protein G-Sepharose beads (Amersham Pharmacia Biotech, Uppsala, Sweden) and $\sim 1 \mu \mathrm{g}$ of antibody overnight at $4^{\circ} \mathrm{C}$. The beads were washed $(2 \times, 10 \mathrm{~min})$ in $500 \mu \mathrm{l}$ of TBS $/ 1 \% \mathrm{NP}-40$ and once in TBS $/ 0.1 \%$ NP-40. Beads were pelleted by centrifugation. b) Magnetic protein G-beads (15 $\mu \mathrm{l}$; Dynal, Hamburg, Germany) were washed two times in phosphate-buffered saline (PBS) buffer. The volume of the bead suspension was adjusted with PBS to $30 \mu \mathrm{l}$ and the suspension was incubated with $1 \mu \mathrm{g}$ of $\mathrm{AB}$ for $30 \mathrm{~min}$ at room temperature (RT). Cell homogenate $(400 \mu \mathrm{l})$ was added and incubated overnight. The beads were then washed $10 \mathrm{~min}$ in TBS $/ 1 \%$ NP-40 and two times $10 \mathrm{~min}$ in TBS/0.1\% NP-40. Beads were pelleted on a magnetic rack. c) Eupergit microbeads (10 $\mu \mathrm{l}$; Miltenyi Biotec, Surrey, United Kingdom; Madore et al., 1999) with covalently bound $\mathrm{mAB}$ OX-7 or $\mathrm{S} 4 \mathrm{AB}$ (negative control), which were kindly provided by Roger Morris (King's College, London, United Kingdom), were incubated with $400 \mu \mathrm{l}$ of rat brain or PC12 cell lysate and incubated overnight at $4^{\circ} \mathrm{C}$. Beads were washed two times $(10 \mathrm{~min})$ in $500 \mu \mathrm{l}$ of TBS $/ 1 \%$ NP-40 and once in TBS/0.1\% NP-40 and pelleted.

Pelleted beads were boiled in $50 \mu \mathrm{l}$ of SDS-sample buffer for $5 \mathrm{~min}$. Control experiments included immunoprecipitations with preimmune sera and irrelevant $\mathrm{mABs}$ as well as precipitations with specific $\mathrm{pABs}$ and $\mathrm{mABs}$, with the use of lysis buffer alone instead of extracts.

\section{Gel Electrophoresis and Immunoblotting}

For SDS-PAGE and immunoblots (Sambrook et al., 1989), proteins were separated on 10 or $12 \%$ minigels under reducing or nonreducing conditions. After gel electrophoresis, proteins were transferred to Hybond-C Super nitrocellulose membranes (Amersham Buchler, Braunschweig, Germany) in a tank blot apparatus. The membranes were air dried, blocked in PBS containing $0.05 \%$ Tween 20 and 3\% nonfat dried milk ( $1 \mathrm{~h}, \mathrm{RT})$ and incubated with the relevant ABs, defined above and below, in blocking solution for $2 \mathrm{~h}$ at RT or overnight at $4^{\circ} \mathrm{C}$. After four washes in PBS $/ 0.05 \%$ Tween 20 , the blots were incubated with HRP-conjugated goat antirabbit or goat antimouse ABs in blocking solution for $2 \mathrm{~h}$ at $\mathrm{RT}$, and, after extensive washing, developed with the use of the enhanced chemoluminescence substrate SuperSignal (Pierce Chemical, Rockford, IL) and ECL hyperfilm (Amersham Buchler).

\section{Immunocytochemistry}

To patch the ganglioside GM1, a preparation of the CTX B subunit was used (Sigma). For internalization experiments, HRP (type VI; Sigma) was added to live cultures for $2 \mathrm{~h}$ at a concentration of 1 $\mathrm{mg} / \mathrm{ml}$ before processing for immunohistochemistry. To label lysosomes, the $\mathrm{pH}$-sensitive probe Lysotracker (Molecular Probes, Eugene, OR) was applied according to manufacturer's instructions.

mABs against the surface proteins Thy- 1 and CD3 as well as CTX were applied to live cells at $37^{\circ} \mathrm{C}$ for $30 \mathrm{~min}$. Cross-linking of surface-bound mABs or CTX was achieved by incubating the cells with goat antimouse and anti-CTX pABs, respectively, for $30 \mathrm{~min}$ at $37^{\circ} \mathrm{C}$. Live cells were incubated with pABs anti-F3 and anti-Thy- 1 $>1 \mathrm{~h}$ at $37^{\circ} \mathrm{C}$. To visualize internalization of Thy-1, the cells were incubated with anti-Thy-1 pAB for $2 \mathrm{~h}$. After cross-linking of surface antigens, cells were permeabilized by immersion in methanol $\left(-20^{\circ} \mathrm{C}, 5 \mathrm{~min}\right)$, followed by fixation in $4 \%$ formaldehyde (FoA; 5 min, RT). After at least three washes in PBS, nonspecific binding sites were blocked with $1 \%$ bovine serum albumin (BSA) in PBS (30 $\mathrm{min}, 37^{\circ} \mathrm{C}$ ). The cells were then incubated with $\mathrm{mABs}$ or rabbit $\mathrm{pABs}$ against reggie-1, -2, caveolin-1, fyn, HRP, limp-2, or phosphotyrosine in blocking solution $\left(2 \mathrm{~h}, 37^{\circ} \mathrm{C}\right)$, washed with PBS, and incubated with the appropriate combination of secondary pABs (1 h, $37^{\circ} \mathrm{C}$ ): either donkey antirabbit (or antimouse) Cy-3 (Dianova, Hamburg, Germany), donkey antigoat (or goat antimouse or goat antirabbit) Alexa 488. The biotinylated Lysotracker probe was detected with the use of streptavidin-Texas Red (Dianova). The cells were washed thoroughly in PBS and coverslipped in Mowiol containing $n$-propylgallate as an antifading agent.

Immunolabeled cells were analyzed under a confocal laser scanning microscope (LSM 510; Zeiss, Oberkochen, Germany) equipped with a Plan-Apochromat $100 \times$ oil immersion lens. Images were acquired with the LSM 510 software and processed further with the use of Photoshop (Adobe Systems, San Jose, CA). The degree of colocalization in double immunostainings was determined by superposition of images acquired in the red and green channels, with the use of the scatter plot or profile functions of the LSM 510 software.

\section{Electron Microscopy}

For EM analysis, rat astrocytes, PC12 cells, and DRG neurons were plated on polylysine-coated Thermanox cell culture plastic discs (Science Services, Munich, Germany) to which laminin (Roche Molecular Biochemicals; for DRG neurons) was added. Astrocytes were removed from Thermanox before processing. Alternatively, rat astrocytes and PC12 cells were grown and fixed in bulk in culture flasks, pelleted, and processed for EM analysis.

Fixation and Embedding. Cells were washed in Hanks' balanced salt solution and then fixed in suspension or as monolayers, with $8 \%$ FoA, prepared from freshly depolymerized para-FoA, in $0.1 \mathrm{M}$ piperazine- $N, N^{\prime}$-bis(2-ethanesulfonic acid); $\mathrm{pH} 7.2,45 \mathrm{~min}$ at $0^{\circ} \mathrm{C}$. Eventually the fixative was supplemented with $0.1 \%$ glutaraldehyde and $1 \mathrm{mM} \mathrm{CaCl}$ to stabilize membranes. After washing with the same buffer, samples were dehydrated in graded ethanol series and embedded in LR Gold (London Resin, London, England). In detail, after $4 \times 30 \mathrm{~min}$ in absolute ethanol, samples were impregnated overnight at $-20^{\circ} \mathrm{C}$ with equal parts of ethanol + LR Gold, followed by LR Gold $+1 \%$ Benzil initiator, three changes of $2 \mathrm{~h}$ each, at $-20^{\circ} \mathrm{C}$, and final embedding and UV-polymerization for $72 \mathrm{~h}$ at a temperature set at $-35^{\circ} \mathrm{C}$ (rising to $-4^{\circ} \mathrm{C}$ due to exothermic reaction, as measured). Samples were left at RT for $1 \mathrm{~d}$ before ultrathin sections were cut and collected on Formvar-coated Nigrids.

Immunogold Labeling. Sections were first floated, $2 \times 10 \mathrm{~min}$, on PBS pH 7.4 and then $10 \mathrm{~min}$ on PBS $+50 \mathrm{mM}$ glycine, followed by 10 min PBS $+0.5 \%$ BSA type BSA-C (BioTrend) $+0.5 \%$ normal goat serum, and finally on $0.5 \%$ BSA-C for $2 \times 10 \mathrm{~min}$, all at RT. Sections were then floated on primary $\mathrm{ABs}$ at concentrations usually $\sim 10$ times above that used for immunofluorescence. The following pABs and $\mathrm{mABs}$ were used: pABs anti-reggie-2, anti-F3, anti-fyn, antilimp-2, and anti-caveolin-1; mABs ESA/anti-reggie-1, anti-Thy-1, and anti-limp-2. In some experiments, anti-Thy-1 mAB was applied to PC12 monolayers before fixation to induce antigen clustering and the resulting ultrathin sections were exposed again to the same ABs.

For immunogold labeling, sections were floated for $1 \mathrm{~h}$ on primary $\mathrm{AB}$ then for $3 \times 10 \mathrm{~min}$ on $\mathrm{PBS}+0.3 \% \mathrm{BSA}-\mathrm{C}$, and finally on 
Anti-Reggie-1 mAB

47-

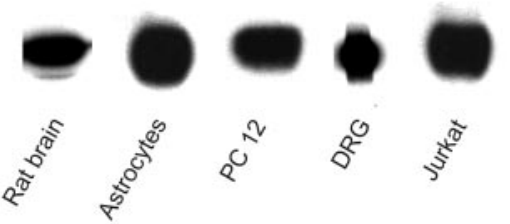

Anti-Reggie-2 pAB

$47=$

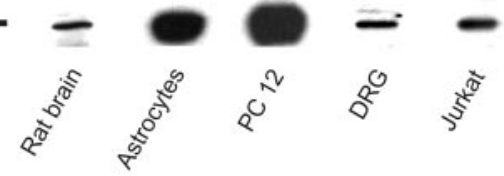

Anti-Caveolin $\mathrm{mAB}$

21-
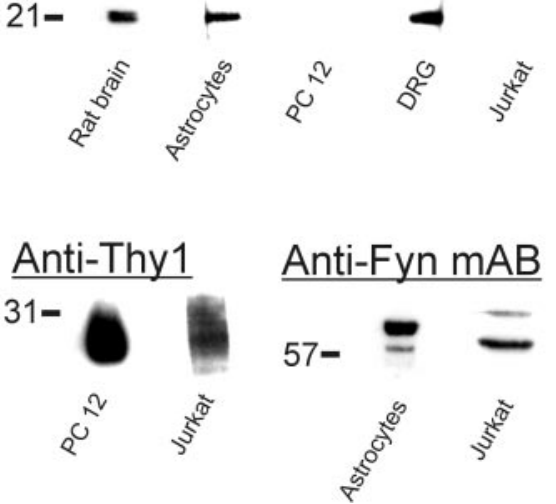

Anti-Reggie-2 mAB

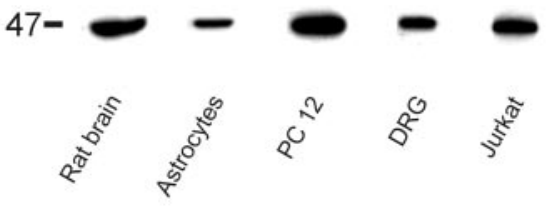

Anti-F3 pAB

135-

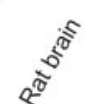

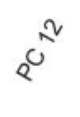

8

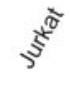

Anti-Caveolin PAB

$21-$<smiles>C1C[Al]C1</smiles><smiles>[CH]1[CH-]CC1</smiles><smiles>C=CCCCC</smiles>

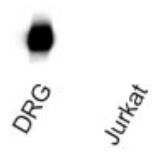

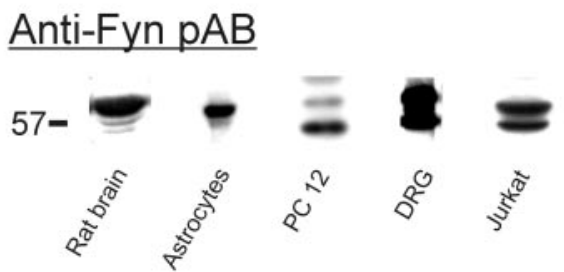

Figure 1. Immunoblots with $\mathrm{ABs}$ against reggie- 1 and reggie-2, caveolin-1, F3, Thy-1, and fyn. Western blot analysis carried out on proteins after SDSPAGE from rat brain, DRGs, astrocytes, PC12 cells, and Jurkat cells, as indicated below each lane, and with the antibodies against reggie- 1 and -2 , caveolin-1, F3, Thy-1, and fyn, as listed above the blots. $\mathrm{mAB}$ antireggie-1 reliably detects $47-\mathrm{kDa}$ reggie- 1 in rat brain and all cells. mAB anti-reggie- 2 and pAB anti-reggie-2 detect $47-\mathrm{kDa}$ reggie-2 in the same tissue and cells. Anti-F3 pAB detects 140kDa F3 in rat brain and DRGs but not in astrocytes, PC12, and Jurkat cells. Anti-caveolin-1 $\mathrm{mAB}$ and $\mathrm{pAB}$ reveal the presence of caveolin-1 in rat brain and astrocytes. Caveolin-1 is not detected in PC12 or Jurkat cells. In DRGs, detection of caveolin-1 results from its presence in closely associated satellite cells, whereas it is not expressed by DRG neurons. Detection of 27kDa Thy-1 was carried out with anti-rat and anti-human Thy-1, respectively, in PC12 and Jurkat cells. Fyn is detected by anti-fyn $\mathrm{mAB}$ and $\mathrm{pAB}$, often as a doublet, of $\sim 57 \mathrm{kDa}$ in rat brain and all cells. secondary AB-gold or pA-gold conjugates. In detail, we used goldconjugates of goat antimouse $\mathrm{AB}$ or $\mathrm{F}(\mathrm{ab})_{2}$ fragments derived therefrom, to detect $\mathrm{mABs}$, or gold-conjugates of $\mathrm{pA}$ to detect $\mathrm{pABs}$. Gold grains used in double labeling studies were of a calibrated diameter of $5 \mathrm{~nm}\left(\mathrm{Au}_{5}\right)$ and $10 \mathrm{~nm}\left(\mathrm{Au}_{10}\right)$, respectively. Goat antimouse$A u_{5,10}$ were from BioTrend or from Sigma, goat antimouse $F(a b)_{2}-$ $\mathrm{Au}_{5}$ from BioTrend, and $\mathrm{pA}-\mathrm{Au}_{5,10}$ from University of Utrecht (Department of Cell Biology, School of Medicine, Utrecht, The Netherlands). Appropriate concentrations were found by varying concentrations and comparison with reference samples of established reactivity (Momayezi et al., 2000).

For double-labeling experiments we combined a pAB-Au and a $\mathrm{pA}-\mathrm{Au}$ conjugate, followed by a $\mathrm{mAB}$ and a goat antimouse $\mathrm{AB}-\mathrm{Au}$ [or a goat antimouse- $\mathrm{F}(\mathrm{ab})_{2}-\mathrm{Au}$ ] conjugate, respectively, with gold grains of different size. They were also applied in inverse sequence, and in some of the controls, gold conjugates were applied without previous application of primary $\mathrm{AB}$ (with negative results). After washing with double-distilled water, sections were stained for 3 min with $2 \%$ aqueous uranyl acetate and washed again. Staining with alkaline lead citrate was not used because this can dislocate and even detach $\mathrm{AB}$ and pA gold conjugates (Momayezi et al., 2000). All samples were analyzed with a Zeiss electron microscope EM10, $30-\mu \mathrm{m}$ objective aperture, $80 \mathrm{kV}$.

\section{RESULTS}

Antibodies against reggie-1 and reggie-2 and antibodies used in subsequent experiments were tested for their spec- ificity in immunoblots with proteins from rat brain, astrocytes, DRGs, PC12 cells, and the human T-lymphocytic Jurkat cell line. mAB anti-reggie-1 (ESA), which specifically recognizes recombinant reggie-1 (and not reggie-2), reveals a band at $47 \mathrm{kDa}$ in rat brain (Lang et al., 1998) and all cells (Figure 1). $\mathrm{mAB}$ anti-reggie-2 as well as affinity-purified reggie-2 $\mathrm{pAB}$, which specifically bind to recombinant reggie-2 (and not reggie-1), recognize a band of $47 \mathrm{kDa}$ in rat brain and all cells (Figure 1). Anti-F3 pAB detects 140-kDa $\mathrm{F} 3$ in rat brain and DRGs. Anti-caveolin-1 $\mathrm{mAB}$ and $\mathrm{pAB}$ reveals the presence of $21-\mathrm{kDa}$ caveolin-1 in rat brain and astrocytes. Caveolin-1 is not detected in PC12 cells and Jurkat cells, and is not found in DRG neurons (Lang et al., 1998) but is detected in immunoblots from DRGs due to the associated satellite cells, which do express caveolin-1. Detection of $27-\mathrm{kDa}$ Thy-1 in PC12 and Jurkat cells was achieved with antibodies specific for rat and human Thy-1, respectively (Figure 1). Anti-fyn $\mathrm{mAB}$ and $\mathrm{pAB}$ detected $57-\mathrm{kDa}$ fyn, sometimes as doublet on the relevant tissue/ cells (Figure 1).

\section{Colocalization of Reggie-1 and Reggie-2 in Plasma membrane Microdomains of Nonactivated Cells}

To determine whether reggie- 1 and reggie- 2 are colocalized in plasma membrane-associated patches and correspond to 

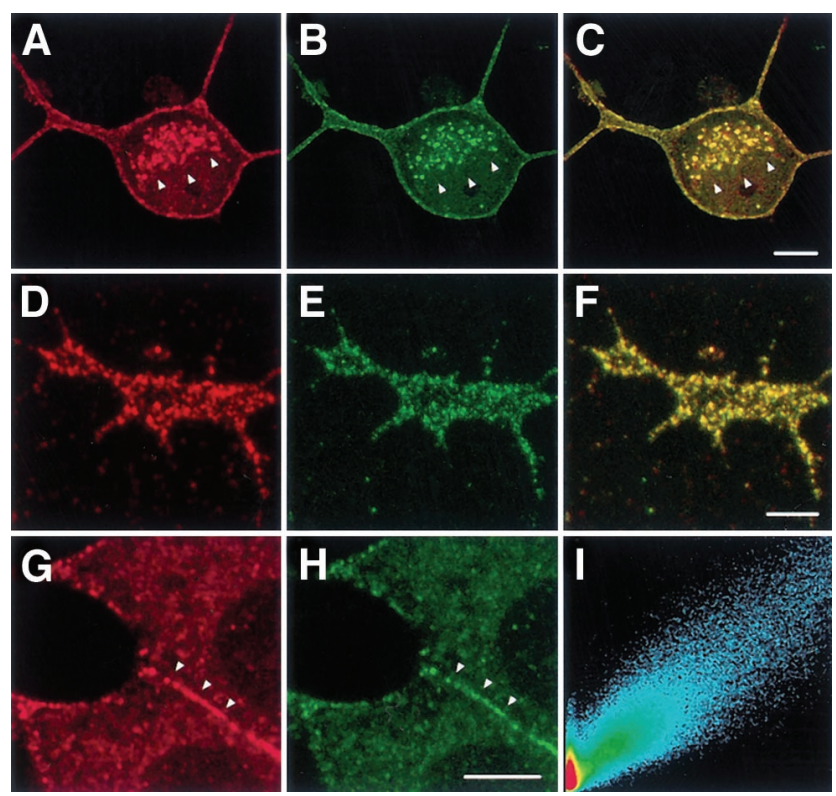

Figure 2. Colocalization of reggie- 1 with reggie- 2 in PC12 cells. An optical section through a PC12 soma shows reggie-1 (a, red) and reggie- $2(b$, green) associated with the plasma membrane and with intracellular compartments (marked by arrowheads). PC12 growth cones show reggie-1 (d) and reggie-2 (e) in the typical punctate distribution. Yellow color in the superposition of red and green channels indicates colocalization of reggie- 1 and -2 (c and f). Reggie-1 and -2 accumulate at cellular contact sites, marked by arrowheads ( $g$ and $h$ ). Scatter plot analysis (i) demonstrates a high degree of colocalization of reggie- 1 and -2. Bars, $5 \mu \mathrm{m}$ (c); $2 \mu \mathrm{m}$ (f); $5 \mu \mathrm{m}$ (h).

microdomains in distribution and size, double immunostaining with anti-reggie- $1 \mathrm{mAB}$ and anti-reggie- $2 \mathrm{pAB}$ was applied to astrocytes, PC12 cells, and DRGs and analyzed by both LSM and EM.

Optical sections examined with LSM (after fixation and permeabilization) reveal punctate staining with anti-reggie-1 $\mathrm{mAB}$ and anti-reggie-2 $\mathrm{pAB}$ along the plasma membrane in all three cell types. This is shown for PC12 cells (Figure 2, a and b; g and h) and their growth cones (Figure $2, \mathrm{~d}$ and e). The punctate yellow immunofluorescence resulting from the merged (red and green) immunofluorescence (Figure 2, c and f) shows that reggie-1 and reggie-2 are colocalized, which is reflected by the scatter plot obtained by the LSM-associated computational function (Figure 2i). In PC12 cells, the punctate distribution of $\mathrm{mAB}$ anti-reggie-1 and $\mathrm{pAB}$ anti-reggie-2 stain is quite conspicuous at cell contact sites (Figure 2, $g$ and $h$ ), a feature also recognized at the EM level (Figure 4b). Astrocytes, subjected to immunostaining with anti-reggie-1 mAB (Figure $3 a$, red) and antireggie-2 pAB (Figure 3b, green) also exhibited a substantial degree of colocalization as is reflected by the yellow immunofluorescence resulting from the merger of the images (Figure 3c) and the corresponding scatter plot (Figure 3d). That reggie- 1 and reggie- 2 are colocalized at the plasma membrane was confirmed by double immunolabeling for reggie- 1 and reggie-2 with the use of gold conjugates of different sizes on ultrathin sections of astrocytes. This resulted in mixed clusters of gold particles at the plasma membrane of
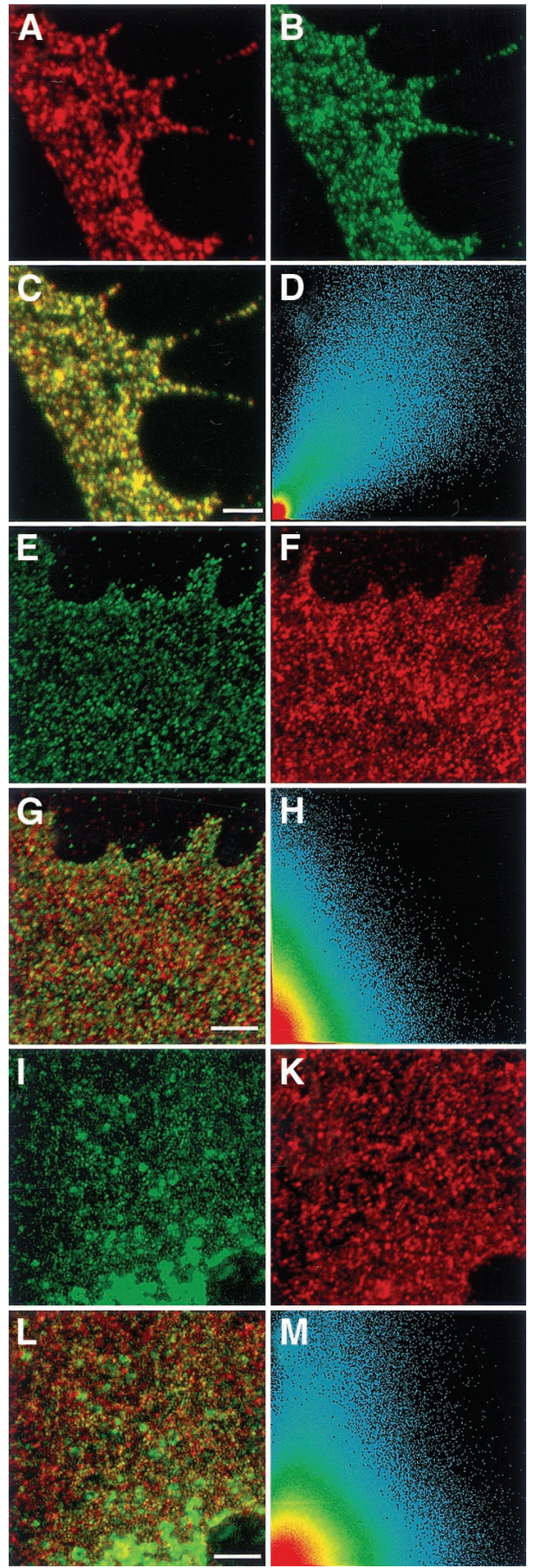

Figure 3. Colocalization of reggie-1 and reggie-2 and lack of colocalization with caveolin-1 in astrocytes. Optical section through processes of astrocytes showing reggie-1 (a, red) and reggie-2 (b, green) staining at the plasma membrane. (c) Superposition of the two images and the scatter plot (d) indicate substantial colocalization of reggie- 1 and -2 . After staining with anti-reggie-1 (e, green) and anti-caveolin-1 ( $\mathrm{f}, \mathrm{red})$, or with anti-reggie-2 (i, green) and anti-caveolin-1 ( $k$, red), the red and green dots remain separate ( $g$ and l) when the images are merged, which is also reflected by the scatter plots (h and m). Bars, $2 \mu \mathrm{m}$ (c); $2 \mu \mathrm{m}$ (g); $5 \mu \mathrm{m}$ (1). 

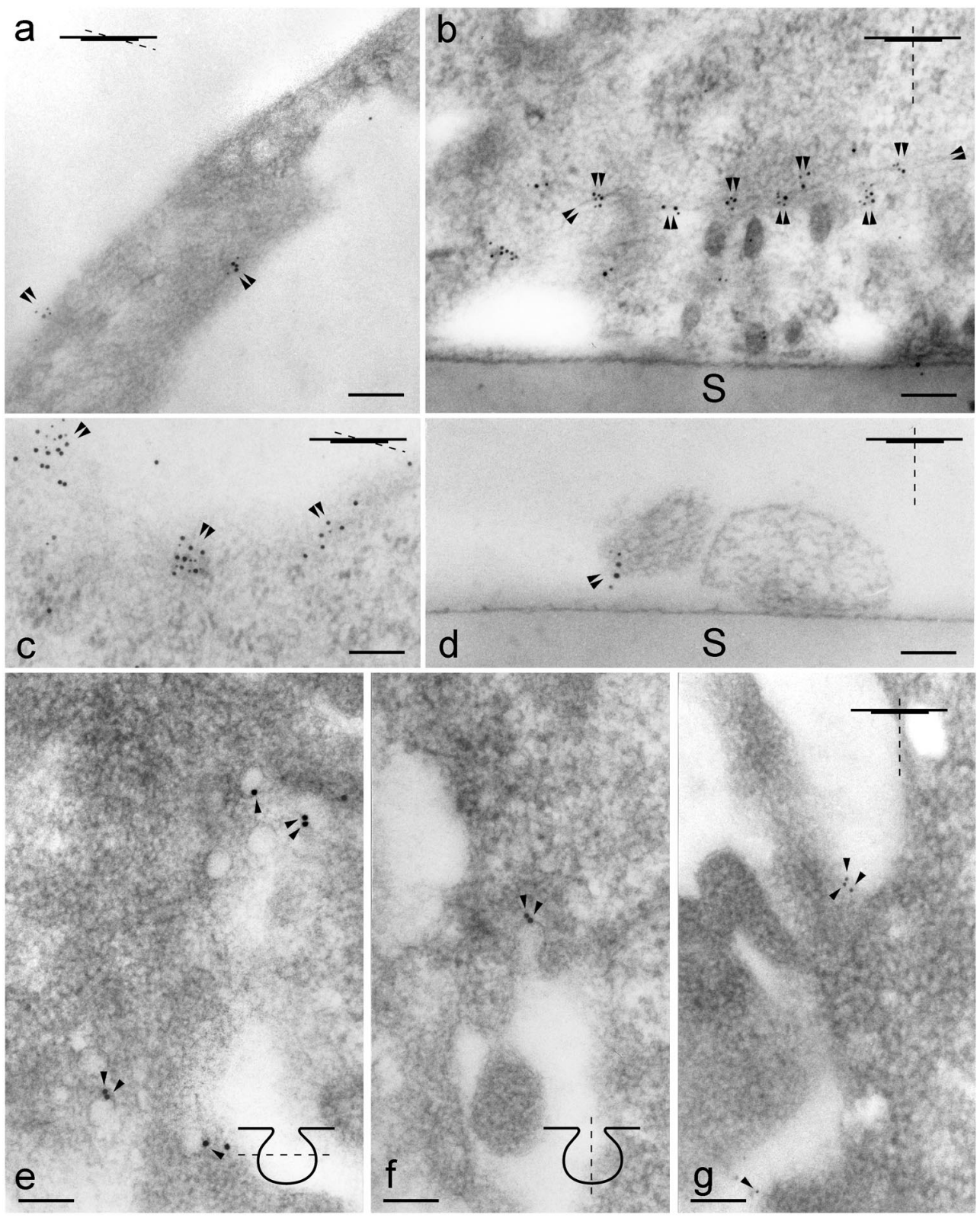

astrocytes (Figure 4a). Such clusters (roughly $0.1 \mu \mathrm{m}$ in diameter) were also seen in ultrathin sections of PC12 cells and DRGs and were independent of the sequence in which $\mathrm{Au}_{5}$ and $\mathrm{Au}_{10}$ gold conjugates were applied.

Astrocytes, in contrast to neurons (Lang et al., 1998; Simons and Toomre, 2000), express caveolin-1 and posses caveolae (Parton, 1996). When astrocytes were subjected to immunofluorescence labeling with $\mathrm{mAB}$ anti-reggie-1 (Figure $3 \mathrm{e}$, green) or $\mathrm{mAB}$ anti-reggie-2 (Figure $3 \mathrm{i}$, green) and $\mathrm{pAB}$ anti-caveolin-1 (Figure 3, $\mathrm{f}$ and $\mathrm{k}$, red), the resulting punctae seen at the LSM remained distinct and separate. This is particularly evident when the images are merged (Figure 3, g and 1). The scatter plot shows that red and green spots are separate (Figure 3, h and $\mathrm{m}$ ). This confirms earlier

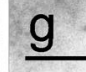

Figure 4. IG EM localization of reggie-1 and -2, Thy-1, fyn, and caveolin-1. Orientation of sections is indicated in the insets. Bars, $0.1 \mu \mathrm{m}$. (a) Astrocyte, double labeling of sections with anti-reggie- $2 \mathrm{pABs}$ and $\mathrm{pA}-\mathrm{Au}_{10}$, followed by anti-reggie-1 $\mathrm{mAB}$ and goat antimouse $\mathrm{F}(\mathrm{ab})_{2}-$ $\mathrm{Au}_{5}$. The area shown is a "grazing" section along the plasma membrane as indicated in the inset. Double labeling occurs in small clusters at the cell periphery (arrowheads). (b) PC12 cell (after cross-linking of Thy-1 in vivo) double labeling on sections with anti-Thy- $1 \mathrm{mAB}$ and goat antimouse- $\mathrm{Au}_{10}$ followed by anti-reggie-2 $\mathrm{pAB}$ and $\mathrm{pA}-\mathrm{Au}_{5}$. Double labeling occurs along apposed cell membranes (arrowheads) of two neighboring cells. S, support. (c) PC12 cell (after cross-linking of Thy-1 in vivo) double labeling on sections with anti-Thy- $1 \mathrm{mAB}$ and goat antimouse $\mathrm{F}(\mathrm{ab})_{2}-\mathrm{Au}_{5}$, followed by anti-reggie- $2 \mathrm{pAB}$ and $\mathrm{pA}$ $\mathrm{Au}_{10}$. Note double labeling of $\sim 0.1-\mu \mathrm{m}$ large microdomains on a grazing section along the plasma membrane. (d) DRG neurites [exposed to anti-fyn $\mathrm{pAB}$ and $\mathrm{pA}-\mathrm{Au}_{10}$ followed by anti-reggie- $1 \mathrm{mAB}$ and goat antimouse $\mathrm{F}(\mathrm{ab})_{2}-\mathrm{Au}_{5}$. Note colocalization (arrowheads) on a neurite. S, support. (e-g) Astrocyte, horizontal (grazing) section (e), and cross section (f) through caveolae and regions devoid of caveolae (g). Micrographs $(\mathrm{e}-\mathrm{g})$ are from the same section. Sections were subjected to double immunogold labeling with anti-caveolin-1 $\mathrm{pAB}$ and $\mathrm{pA}-\mathrm{Au}_{10}$ and to anti-reggie-1 $\mathrm{mAB}$ and goat antimouse $\mathrm{F}(\mathrm{ab})_{2}-\mathrm{Au}_{5}$. $\mathrm{Au}_{10}$ gold grains label caveolae (e and $\mathrm{f}$, arrowheads) where $\mathrm{Au}_{5}$ gold grains are not found. (g) $\mathrm{Au}_{5}$ gold grains indicating the presence of reggie-1 are detected in regions of the plasma membrane clearly distinct from caveolae and anti caveolin-1 $\left(\mathrm{Au}_{10}\right)$ label. data showing that reggie-1 is not colocalized with caveolin-1 in astrocytes (Lang et al., 1998) and is consistent with IG EM results.

To corroborate our previous data (Lang et al., 1998) we subjected ultrathin sections through astrocytes to double immunogold labeling with anti-reggie- $1 \mathrm{mAB}$ and anti-reggie-2 $\mathrm{pA}$, and anti-caveolin- $1 \mathrm{pAB}$ and anti-reggie- $1 \mathrm{mAB}$. Figure $4(\mathrm{e}-\mathrm{g})$ are from one and the same section and show that gold clusters $\left(\mathrm{Au}_{10}\right)$ detecting caveolin- 1 are localized to the flask-shaped invaginations, i.e., caveolae (Figure 4, e and $\mathrm{f})$, where no reggie-1 $\left(\mathrm{Au}_{5}\right)$ gold grains were found. The reggie- $1\left(\mathrm{Au}_{5}\right)$ gold grains are at the plasma membrane in regions where no caveolae existed and from where caveolin-1 $\left(\mathrm{Au}_{10}\right)$ gold grains were absent (Figure $\left.4 \mathrm{~g}\right)$. Thus, ac- 

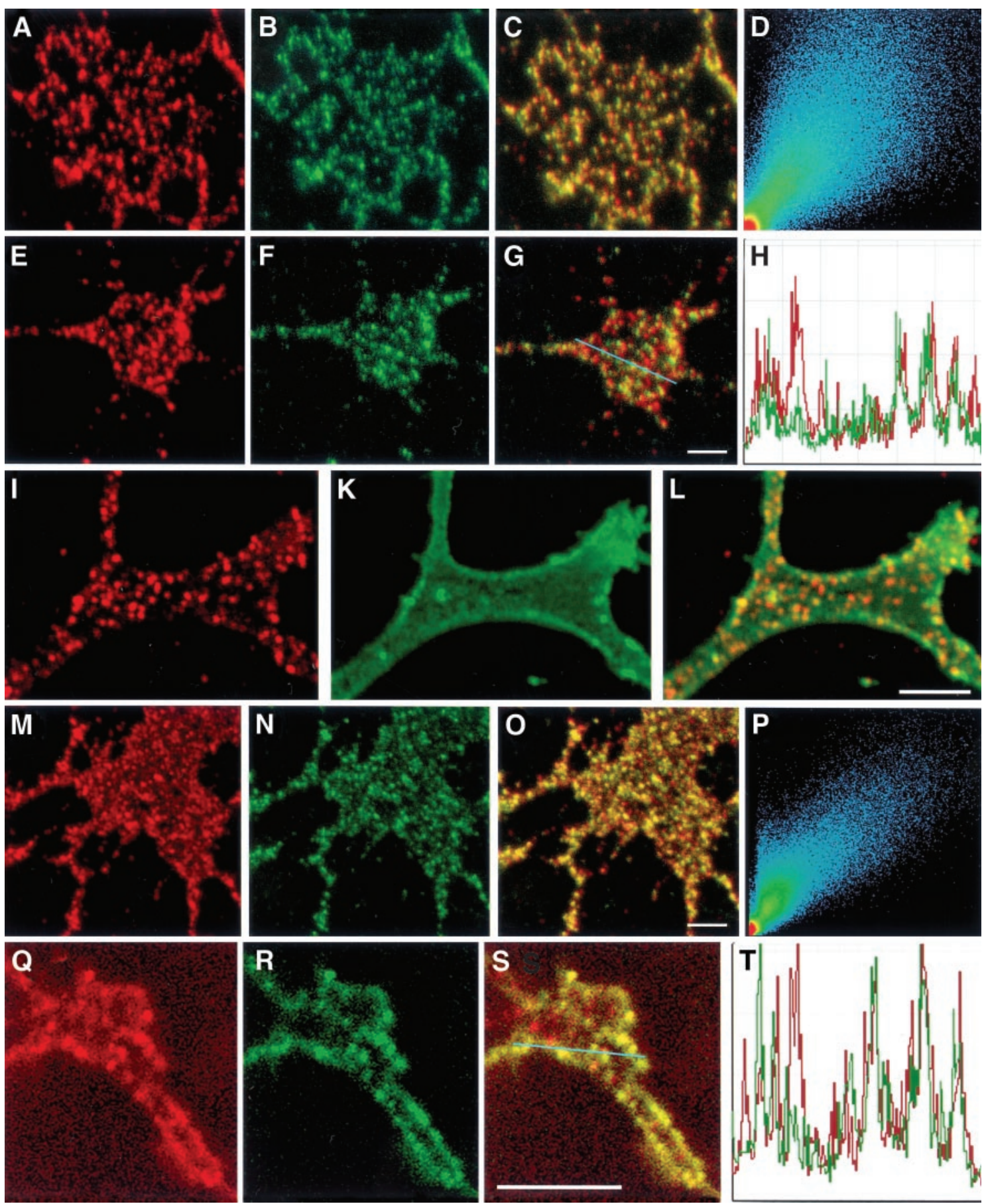

Figure 5. Colocalization of reggie and F3, reggie and Thy-1, and fyn. After AB cross-linking, F3 immunostaining (a, red) in DRG growth cones closely resembles anti-reggie-1 labeling (b, green). Colocalization of F3 and reggie-1 staining is demonstrated by superposition of red and green channel images (c) as well as in the corresponding scatter plot (d). (e) Fyn immunoreactivity (red) also shows a punctate pattern in growth cones, like that of reggie-1 (f, green). Partial colocalization of fyn and reggie- 1 is evident from the superimposed images (g, yellow dots) and a profile of both immunostaining patterns (h), along the blue line in (q). PC12 cell growth cone labeled with anti-reggie-1 (i, red) and showing its typical dotted distribution (I and 1), whereas labeling with anti-Thy-1 before cross-linking results in a homogenous distribution ( $k$, green). Cross-linking of Thy-1 results in a punctate distribution ( $n$, green) resembling that of anti-reggie- 1 (m, red) and with substantial colocalization of reggie- 1 and Thy-1, as is reflected by the superposition of the two images (o, yellow dots) and the corresponding scatter plot (p). Staining of PC12 growth cone with anti-fyn gives a punctate distribution (q, red) like that emerging after cross-linking of Thy-1 ( $r$, green). The merger of the images ( $\mathrm{s}$, yellow dots) shows partial colocalization of fyn and Thy-1, which is also seen in the distributional profile ( $\mathrm{t}$, across the blue line in $\mathrm{s})$. Bars: $2 \mu \mathrm{m}$. 


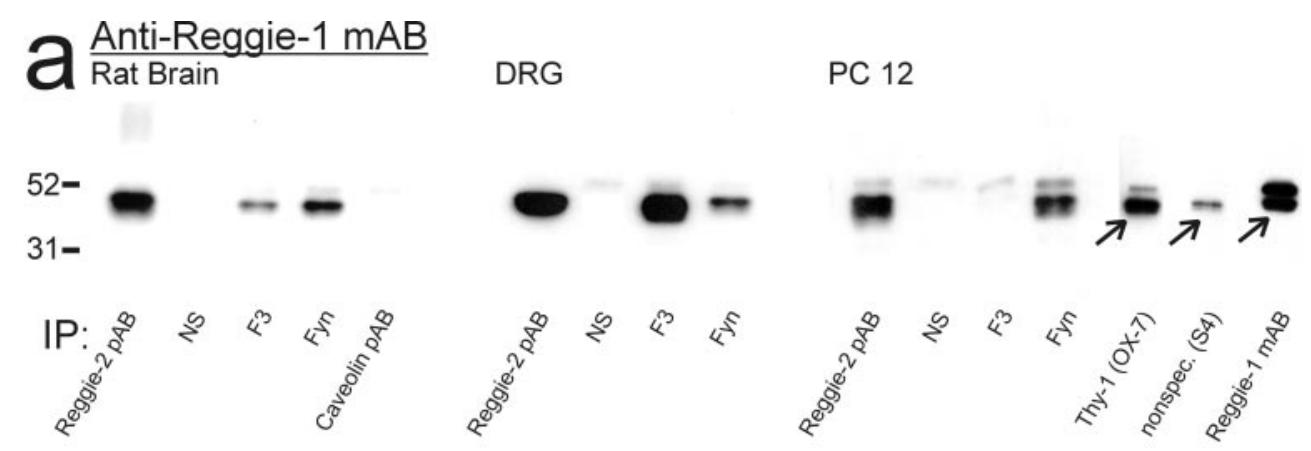

Figure 6. Immunoblot analysis of reggie- 1 and -2 in coimmunoprecipitates. Immunoprecipitation: $\mathrm{ABs}$ used for immunoprecipitation, as listed below each lane. Immunoblots of rat brain, DRGs, and PC12 cells $(a-c)$, of astrocytes (c), and Jurkat cells (d) were probed with ABs: anti-reggie-1 $\mathrm{mAB}$ (a); anti-reggie-2 $\mathrm{mAB}$ and anti-fyn pAB (b); anti-caveolin-1 $\mathrm{mAB}$, anti-reggie-1 $\mathrm{mAB}$, and anti-reggie-2 $\mathrm{mAB}$ (c); and anti-reggie-1 $\mathrm{mAB}$, anti-reggie-2 $\mathrm{mAB}$, and anti-fyn pAB (d), respectively, as listed above the blots. Molecular weight markers are indicated to the left. (a) Reggie-1 is detected in immunoprecipitates with anti-reggie-2 and anti-fyn $\mathrm{pABs}$ from extracts of rat brain, DRGs, and PC12 cells. Coimmunoprecipitation of reggie-1 by anti-caveolin-1 pAB is not detectable. Anti-F3 pABs coprecipitate reggie-1 from extracts of rat brain and DRGs, but not from PC12 cells, which do not express F3. Anti-Thy-1 mAB (OX-7, coupled to Eupergit beads), coprecipitates reggie- 1 from PC12 cells. Only a small amount of reggie-1 is seen after precipitation with an irrelevant $\mathrm{AB}$ (S4, coupled to the same Eupergit beads) due to nonspecific binding of reggie- $1 \mathrm{mAB}$. Reggie-1 mAB (coupled to Dynabeads) precipitates reggie-1. Specific bands are marked by arrows. The bands above the specific reggie signal are due to the binding of secondary $\mathrm{ABs}$ to heavy chains of the precipitating ABs. (b) Reggie-2 is precipitated from rat brain extracts by anti-reggie-2 $\mathrm{pAB}$, and, like reggie-1 (a), coprecipitates with F3 and fyn. Again, reggie-2 does not coprecipitate with caveolin-1 pAB. Reggie-2 $\mathrm{mAB}$ (coupled to Dynabeads) precipitates reggie-2 in PC12 cells (arrow). The bands above the specific reggie signal are due to
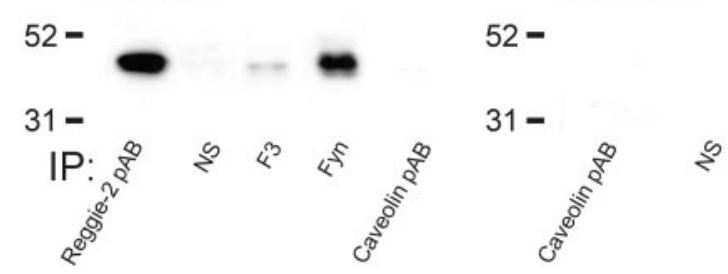

the binding of secondary $\mathrm{ABs}$ to heavy chains of the precipitating $\mathrm{ABs}$ (control with secondary $\mathrm{AB}, 2 \mathrm{nd}$ only). Fyn mAB and Thy-1 mAB (OX-7, coupled to Eupergit beads) coprecipitates reggie-2 (arrows), but not the irrelevant AB S4 (on beads). Anti-fyn mAB (coupled to Dynabeads) precipitates fyn in PC12 cells and fyn is coprecipitated by anti-Thy-1 mAB (OX-7 on Eupergit beads). S4 on Eupergit beads as control. (c) Caveolin-1 is not detected after coimmunoprecipitation with anti-reggie-2 pAB or anti-F3 and anti-fyn pABs (rat brain), nor with anti-reggie-2 mAB (astrocytes), but is precipitated by anti-caveolin pAB. Anti-caveolin pAB and anti-reggie-2 mAB were coupled to Dynabeads. Anti-caveolin-1 pAB immunoprecipitates caveolin-1, but caveolin-1 is not coprecipitated by anti-reggie-2 or by anti-F3 or anti-fyn pABs. Reggie-1 is coimmunoprecipitated by anti-reggie- 2 pAB and anti-fyn pAB in astrocytes, yet not by anti-caveolin pAB. Anti-caveolin pAB does not coprecipitate reggie-2. (d) In Jurkat cells, reggie-1 is coimmunoprecipitated by anti-reggie-2 pAB and mAB (arrow), by anti-fyn and anti-Thy- 1 mABs (arrow) and is precipitated by anti-reggie-1 mAB. Preimmune sera (NS) and mouse IgG served as controls. All mABs were coupled to Dynabeads. Fyn, revealed by anti-fyn pAB in homogenates of Jurkat cells, is detected after coimmunoprecipitation with anti-Thy-1 mAB and anti-reggie-2 mAB (arrows) but no such bands appear after coprecipitation with nonspecific mouse IgG. Reggie-2 is coimmunoprecipitated by anti-fyn $\mathrm{pAB}$ and detected by anti-reggie- $2 \mathrm{mAB}$. 
cording to our LSM and IG EM analysis, reggie-1 and reg-
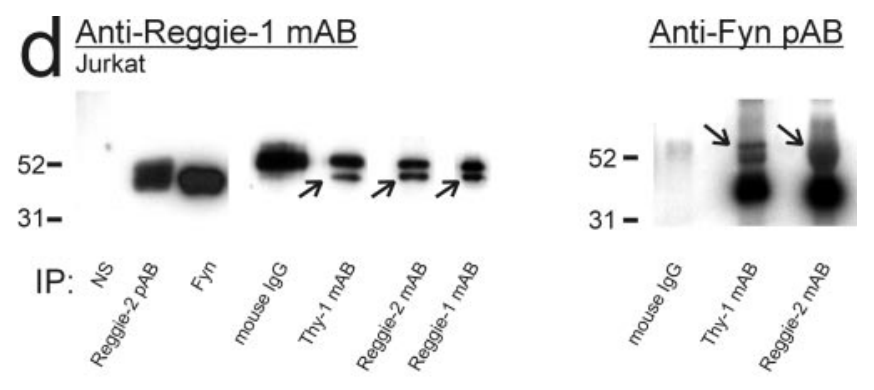

Anti-Reggie-2 mAB

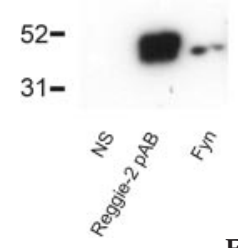

Figure 6 (legend on facing page).

gie-2 form microdomains in astrocytes outside of and distinct from caveolae.

In neurons that are known to be devoid of caveolin- 1 and caveolae (Lang et al., 1998; Simons and Toomre, 2000), reggie-1 and -2 also occur in discrete plasma membrane microdomains that are present before treatment that induces clustering of GPI-anchored cell surface proteins.

\section{Activated GPI-anchored CAMs Preferentially Assemble in Reggie Microdomains}

LSM and IG EM analyses were carried out to determine whether activated GPI-anchored CAMs associate selectively with microdomains defined by reggie. Anti-Thy-1 mAB was applied to living PC12 cells and anti-F3 pAB to DRGs to activate the CAMs. After fixation and permeabilization, double labeling experiments were performed with the appropriate combination of $\mathrm{pABs}$ and $\mathrm{mABs}$ against reggie-1 and -2 , respectively.

The activation of F3 leads to the formation of F3 patches along the DRG neurites and growth cones, which can be seen in optical LSM sections (Figure 5a, red). Superposition with images showing the anti-reggie-1 dots (Figure 5b, green) gives yellow punctae (Figure 5c), indicating colocalization. This is reflected in the scatter plot for these images (Figure 5d). Whereas the detection of surface-associated F3 through anti-F3 pAB in DRGs always produced a punctate pattern (most likely because pABs are capable of crosslinking their respective antigen in PFA fixed cells; Madore et al., 1999), application of anti-Thy- $1 \mathrm{mAB}$ to PC12 cells, which were fixed before staining, resulted in a homogeneous, i.e., nonpunctate staining (Figure 5k). Anti-reggie-2 pAB, however, produced the same punctate staining pattern (Figure 5, $i$ and 1 ) as illustrated in Figure 2. Activation of Thy- 1 by anti-Thy-1 pAB application before fixation results in a punc- tate distribution of this GPI-linked CAM (Figure 5n, green) and leads to selective coclustering with micropatches defined by reggie-2 (Figure $5 \mathrm{~m}$, red). This is supported by the merger of the two images (Figure 5o) and the corresponding scatter plot (Figure 5p). These results indicate that the activated GPI-linked CAMs, F3 and Thy-1, cocluster with reggie-1 and -2 microdomains.

At the EM level, double immunolabeling with $\mathrm{Au}_{10}$-conjugated secondary $\mathrm{ABs}$ to localize anti-reggie-2, and $\mathrm{Au}_{5^{-}}$ conjugated secondary ABs to visualize anti-Thy-1 were performed after Thy-1 activation. Figure 4 (b and c) demonstrates distinct clusters, roughly $0.1 \mu \mathrm{m}$ in diameter, containing both sizes of gold particles at the plasma membrane of PC12 cells. Mixed gold grain clusters were conspicuous at contact sites between PC12 cells (Figure 4b) where a striking assembly of reggie-1 and -2 was noted in LSM analysis (Figure 2, g-i). This LSM/IG EM analysis suggests that activated GPI-anchored CAMs on the cell surface copatch with preexisting reggie- 1 and reggie-2 microdomains.

IG EM analysis in DRGs, with $\mathrm{Au}_{10}$ and $\mathrm{Au}_{5}$-coupled ABs against F3 and reggie-1, respectively, reveals clusters containing both types of gold grains at the plasma membrane (roughly $0.1-0.2 \mu \mathrm{m}$ in diameter). Despite the low frequency of DRG neurites and their small size we found mixed gold grain clusters in four sections (20 sections in different regions were examined and two had only $\mathrm{Au}_{5}$ grains). Because F3 appears to be selectively associated with microdomains defined by reggie- 1 and -2 , and because activation of F3 can elicit signal transduction that involves the tyrosine kinase fyn, we examined in DRGs whether this implies that fyn is colocalized with reggie proteins. Similar experiments were carried out concerning Thy-1 and fyn in PC12 cells.

Immunofluorescence labeling with anti-fyn pAB and subsequent LSM analysis shows punctate staining along the DRG plasma membrane (Figure 5e, red) with a frequency similar to that with anti-reggie-1 mAB (Figure $5 f$, green). The merged image (Figure 5g) and the distributional profile of punctae across the growth cones (Figure 5h) show the existence of red, green, and yellow dots, suggesting that fyn is often, yet by no means exclusively, colocalized with anti-reggie- 1 . Therefore, the distributional profile was used to show the limited but noticeable degree of colocalization. Because fyn interacts with a variety of proteins (Lang et al., 1998), it is not surprising that anti-fyn staining also occurs outside the reggie clusters. When IG EM analyses on DRGs were carried out with the use of $A u_{10}$ and $\mathrm{Au}_{5}$ gold for the detection of reggie- 1 and fyn, mixed gold clusters were observed (Figure $4 \mathrm{~d}$ ). $\mathrm{Au}_{5}$ gold grains for the detection of anti-fyn occurred more often as individual gold grains rather than as clusters. A similar situation was observed when the distribution of fyn and Thy- 1 was analyzed in PC12 cells. The punctate staining with anti-Thy-1 pAB (Figure 5r, green) and anti-fyn $\mathrm{mAB}(5 \mathrm{q}$, red) resulted in a partial colocalization (Figure 5s, yellow; and distributional profile, 5t). These results, showing that fyn can be found in association with reggie microclusters and cross-linked GPI-linked CAMs, are confirmed below by coimmunoprecipitation experiments.

\section{Coimmunoprecipitation of Reggie-1, Reggie-2, F3, Thy-1, and fyn}

To determine whether colocalization is paralleled by a biochemical association of the proteins of interest, a series of coimmunoprecipitation experiments and Western blot anal- 
yses were carried out with proteins from rat brain, astrocytes, PC12 cells, and DRGs. Reggie-2, and most importantly, reggie- 1 is reliably detected in the precipitate with both anti-reggie- $2 \mathrm{pAB}$ and $\mathrm{mAB}$ (coupled to Dynabeads) as the precipitating $\mathrm{AB}$. Results achieved with anti-reggie-2 $\mathrm{pAB}$ are demonstrated by the Western blot analysis of the coimmunoprecipitated proteins from brain, DRGs, PC12 cells (Figure 6a), and astrocytes (Figure 6c). Anti-reggie-1 $\mathrm{mAB}$ (with and without coupling to Dynabeads) does apparently not coprecipitate reggie-2, because there is no detection of reggie-2 with the relevant ABs in Western blots of the precipitates. However, the finding that reggie-2 ABs coprecipitate reggie- 1 suggests that reggie- 1 and -2 are associated, a finding confirmed below by coimmunoprecipitations with F3, Thy-1, and fyn ABs. Further, coupling of ABs to beads does not cause unspecific coimmunoprecipitation, as is also demonstrated by the control experiments (Figure 6).

With $\mathrm{pAB}$ anti-F3 as the precipitating $\mathrm{AB}$, the Western blots of the precipitate reveal the presence of reggie-1 (Figure 6a) and reggie-2 (Figure $6 \mathrm{~b}$ ) in rat brain, and of reggie-1 in DRGs (Figure 6a). But as expected, no such signal is observed with $\mathrm{mAB}$ anti-reggie-1 in PC12 cells that do not express F3 (Figure 6a). This provides an internal control for the specificity of the procedure. A further control consisted in the use of preimmune sera (Figure 6, a-c). When coimmunoprecipitation is performed in PC12 cells with $\mathrm{mAB}$ anti-Thy-1/OX-7 (which was coupled to Eupergit beads), both reggie- 1 and reggie- 2 are detected in the precipitate (Figure 6, a and b) and so is fyn (Figure 6b). The control antibody S4 coupled to the same beads did not precipitate reggie- 2 or fyn, and only a trace of reggie- $1 \mathrm{mAB}$ binding was detected. When coimmunoprecipitation is performed with anti-fyn $\mathrm{pAB}$, reggie- 1 is found consistently in the immunoprecipitate in brain and all cell types tested (Figure 6, a-c). Anti-fyn pAB also coimmunoprecipitates reggie-2 from rat brain and PC12 cells (Figure $6 \mathrm{~b}$; for Jurkat cells, see Figure $6 \mathrm{~d}$ ). These data suggest that reggie-1 and reggie- 2 are associated with fyn, as well as with F3 and Thy-1 in those tissues and cells that express these GPI-linked CAMs.

\section{Reggie-1 and -2 Are not Associated with Caveolin-1 in Rat Brain and Astrocytes}

When anti-caveolin-1 pAB was used as the precipitating $A B$, neither reggie-1 nor reggie-2 was detected in the precipitate from rat brain (Figure 6, a and b). Moreover, when proteins precipitated by anti-reggie-2, anti-F3, and anti-fyn pABs were analyzed in Western blots with anti-caveolin-1 mAB, no trace of caveolin-1 was detected (Figure 6c). Anti-caveolin-1 pAB, however, did precipitate caveolin-1 (Figure 6c). When coimmunoprecipitation experiments were performed with astrocytes, with the use of anti-reggie- 2 pAB, reggie-1 was reliably detected, yet not caveolin-1 (Figure 6c). The precipitate of anti-caveolin pAB contained caveolin-1 but neither reggie-1 nor reggie-2 (Figure 6c). These experiments were repeated with anti-caveolin- $1 \mathrm{mAB}$ with the same result (not shown). These results are not only consistent with the notion that there is no spatial or functional association of caveolin-1 with reggie proteins but also underscore the fact that reggie- 1 and - 2 form microdomains distinct from caveolae (see above; Lang et al., 1998).

\section{Reggie Microdomains in Jurkat Cells/T Lymphocytes}

In $\mathrm{T}$ lymphocytes, activation of Thy-1 (through AB crosslinking) leads to the coassembly of Thy-1, the T-cell receptor complex and associated proteins, and fyn in one aspect of the cell (capping; Harder et al., 1998) so as to increase the efficacy of signal transduction (Janes et al., 1999). Capping is also observed after application of pAB anti-CTX, which binds to the ganglioside GM1 (Janes et al., 1999) and leads in some cells to the emergence of a bulging cap. Previous data (Harder and Simons, 1999) obtained with double immunofluorescence microscopy in activated cells have shown the accumulation of the relevant molecules in patches of irregular size and shape. To determine whether reggie- 1 and -2 are expressed in T lymphocytes and participate in the capping event and in associated signal transduction, we analyzed the human Jurkat T cells by LSM, before and after stimulation with anti-cholera toxin pABs or anti-Thy-1 mAB (Figure 7).

In stimulated cells reggie- 1 and reggie-2 showed significant colocalization in patches (Figure 7, a-c). After induction of Thy-1 clustering (Figure 7e), reggie-1 accumulated at the area of the cell where Thy- 1 patches (Figure 7d) were localized, and as the merger of the two immunofluorescence images reveals, most of the reggie- 1 is colocalized with Thy-1 (Figure 7f). A very similar situation was observed after induction of capping by anti-CTX pAB. When antireggie- $1 \mathrm{mAB}$ staining (Figure $7 \mathrm{~g}$ ) is combined with anti-fyn pAB staining in activated cells (Figure $7 \mathrm{~h}$ ), both are found condensed in patches in the same area of the cell where they are partially colocalized (Figure $7 \mathrm{i}$ ). The same is true of anti-T-cell receptor/CD $3 \mathrm{mAB}$. Furthermore, anti-fyn mAB (Figure 7k) is partially colocalized with anti-Thy-1 pAB stain (Figure 7l) as is evident in the merged images (Figure $7 \mathrm{~m}$ ). Unstimulated Jurkat cells show staining along the circumference of the cell when exposed to anti-reggie-1 mAB (Figure $7 \mathrm{n}$ ), and exhibit staining with anti-Thy-1 pAB (Figure 7o) and anti-fyn $\mathrm{mAB}$ (Figure 7p), with no indication of significant condensation in patches or colocalization. Reggie-2 is also found around the circumference of unstimulated cells (Figure 7r) but colocalization of plasma membrane-associated reggie-1 (Figure 7q) and reggie-2 (Figure 7, q-s) is less apparent than in stimulated cells or neurons (Figure 2). There are occasional yellow spots of merged reggie-1 and -2 stain at the plasma membrane but most of the colocalized reggie- 1 and -2 are in intracellular globular organelles (Figure $7 \mathrm{~s} ; \mathrm{a}-\mathrm{c}$; $\mathrm{d}$ and $\mathrm{f} ; \mathrm{g}-\mathrm{l} ; \mathrm{k}$ and $\mathrm{m}$ ), suggesting that copatched reggie is rapidly internalized in Jurkat cells. In activated cells, as shown by Harder and Simons (1999), anti-phosphotyrosine $\mathrm{mAB}$ produces significant staining in the region of the capped proteins (Figure $7 \mathrm{t}$ ) where it is colocalized with anti-Thy-1 pAB staining (Figure $7 \mathrm{u}$ ), demonstrated by the yellow patches in the merged images (Figure $7 \mathrm{v}$ ). Antireggie-2 pAB staining is observed in the same region of the cell as antiphosphotyrosine immunoreactivity (Figure 7, w and $x$ ) and both are colocalized to some extent (Figure 7y). In contrast to stimulated cells where antiphosphotyrosine accumulates preferentially in the cap, antiphosphotyrosine staining is distributed over the cell's circumference (Figure $\left.7 w^{\prime}\right)$ in unstimulated cells (Harder and Simons, 1999).

This demonstrates that reggie- 1 and -2 are specifically recruited to the sites where activated T-cell receptor, GM1 patched by CTX, Thy-1, and fyn kinase assemble and where 

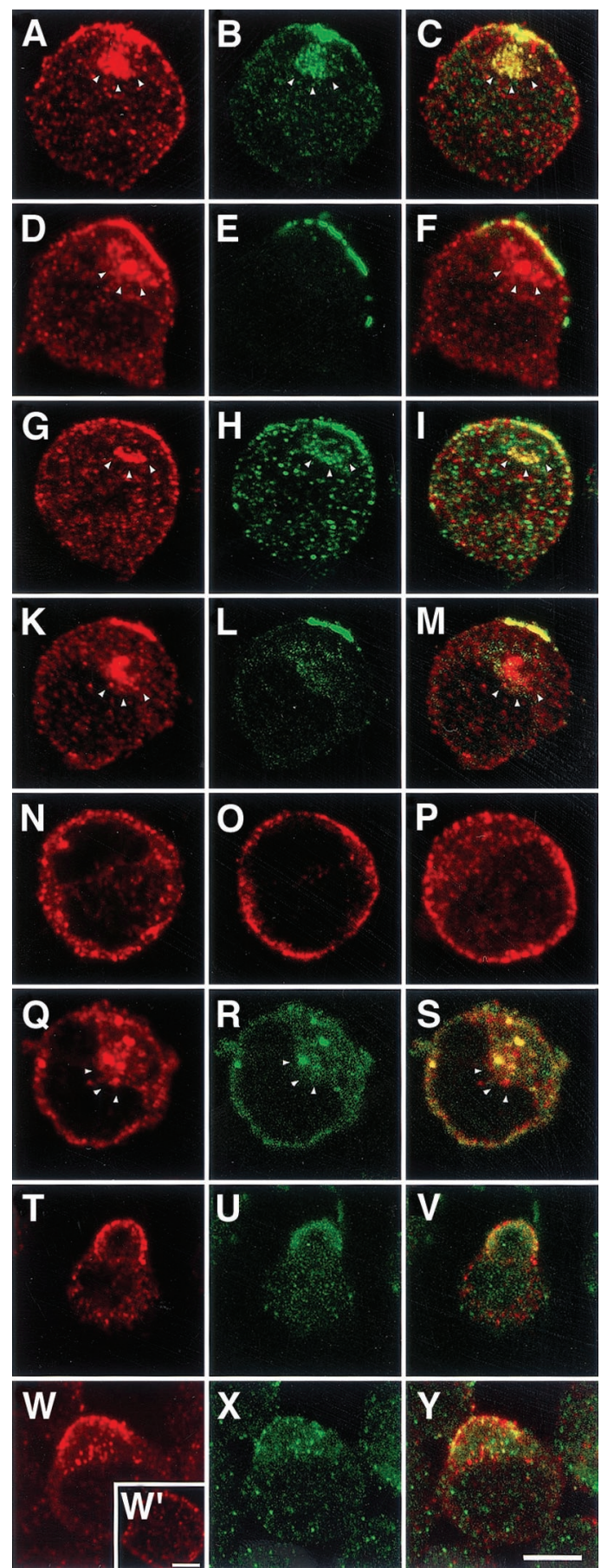

Figure 7. Capping-induced translocation of reggie in Jurkat cells. In stimulated Jurkat cells, anti-reggie-1 (a, red) and anti-reggie-2 (b, green) accumulate preferentially at one aspect of the cell where they show substantial colocalization in patches (c, yellow). Reggie-1 (d, red) exhibits a substantial degree of colocalization with Thy-1 (e, green) as reflected by the merged images ( $\mathrm{f}$, yellow), and so does reggie- 1 ( $\mathrm{g}$, red) and fyn (g, green) as seen in $\mathrm{i}$, and fyn $(\mathrm{k}, \mathrm{red})$ and Thy- 1 (l, green) as seen in $\mathrm{m}$. Optical sections of unstimulated Jurkat cells show the unpatched distribution of reggie-1 (n), Thy-1 (o), and fyn (p), and of reggie-1 (q) and reggie-2 ( $\mathrm{r}$ and $\mathrm{s}$ ). The white arrowheads mark the intracellular accumulation of the respective antigens in endolysosomal increased phosphorylation and signaling occur (Thomas and Samelson, 1992; Harder et al., 1998).

Coimmunoprecipitation assays with anti-reggie- $2 \mathrm{pAB}$ and $\mathrm{mAB}$, anti-Thy- $1 \mathrm{mAB}$, and anti-fyn pAB (and the relevant controls) were carried out with proteins of Jurkat cells to determine whether reggie is associated with Thy-1 and fyn kinases in this cell type. When analyzed in Western blots with anti-reggie- $2 \mathrm{pAB}$ and anti-reggie- $1 \mathrm{mAB}$, the reggie-2 immunoprecipitate contained both reggie-1 and reggie-2 (Figure 6d). The precipitate obtained with anti-Thy-1 mAB contained reggie-1 and fyn, as is shown in Western blots with the use of anti-reggie- $1 \mathrm{mAB}$ and anti-fyn pAB (Figure $6 \mathrm{~d})$. Moreover, with anti-fyn $\mathrm{pAB}$ as precipitating $\mathrm{AB}$, Western blots detect reggie-1 and reggie-2 in the precipitate (Figure $6 \mathrm{~d}$ ). As was the case with rat brain and neurons, antireggie-1 $\mathrm{mAB}$ did not coimmunoprecipitate reggie- 2 . Caveolin-1 and F3 are not expressed in T lymphocytes (Harder and Simons, 1997).

Thus, reggie- 1 and -2 become redistributed along with the activated T-cell receptor complex, cross-linked Thy-1, and CTX-patched GM1 are colocalized with anti-phosphotyrosine staining and are associated with fyn. Reggie-1 and -2 are therefore found at strategic sites where signal transduction takes place.

\section{Reggie-1 and -2 Become Localized to Endolysosomes}

In addition to their association with the plasma membrane, reggie-1 and reggie-2 were observed in globular organelles in PC12 cells (Figure 2, a-c), Jurkat cells (Figure 7), and astrocytes (Figure 8). To identify the organelles that contain reggie immunoreactivity, ABs against marker proteins of the Golgi and endolysosomes were applied. Astrocytes were the preferred cells for this analysis because of their larger size and abundance of intracellular globular elements. In LSM analysis of astrocytes, the endolysosomes containing reggie-1 protein (Figure $8, \mathrm{~b}$ and e) accumulated exogeneous HRP (Figure 8, a and c), were also labeled by Lysotracker (Figure 8, d-f), a marker for acidic compartments, and were stained by anti-limp-2 pAB (Figure $8, \mathrm{~h}-\mathrm{i}$ ), suggesting that reggie- 1 is transported to endolysosomes for degradation. IG EM analysis of astrocytes with $\mathrm{Au}_{5}$-coupled secondary $\mathrm{ABs}$ for the detection of anti-limp-2 and $\mathrm{Au}_{10}$-coupled secondary $\mathrm{ABs}$ for the detection of anti-reggie-2 showed that limp-2 is associated with the endolysosome membrane and reggie-2 with its amorphous contents.

In Jurkat cells, after Thy-1 or CTX clustering, endolysosomes containing reggie- 1 accumulate in the region underneath the capped proteins (Figure $8, j-1$ ) where they may merge to form larger vacuoles. In cells stimulated with anti-Thy-1 ABs for 1-2 $h$, there was a marked decrease of plasma membrane-associated anti-reggie-1, anti-Thy-1, and anti-fyn staining and a concurrent increase of staining in endolysosomes with anti-reggie- 1 and anti-Thy-1 (Figure 8, $\mathrm{j}-1$ ); anti-reggie-1 and anti-fyn antibodies (Figure 8, $\mathrm{m}-\mathrm{o}$ );

Figure 7 (cont). compartments. Capping of Thy- 1 by AB crosslinking $(\mathrm{t})$ leads to increased phosphotyrosine staining $(\mathrm{u})$, partially colocalized with Thy-1 immunoreactivity (v). Moreover, phosphotyrosine $(w)$ and reggie-2 pAB immunostaining $(x)$ partially colocalize $(y)$ in cells stimulated by cross-linking of Thy-1. The inset $\left(\mathrm{w}^{\prime}\right)$ shows the distribution of phosphotyrosine in unstimulated cells. Bars, $5 \mu \mathrm{m}$. 

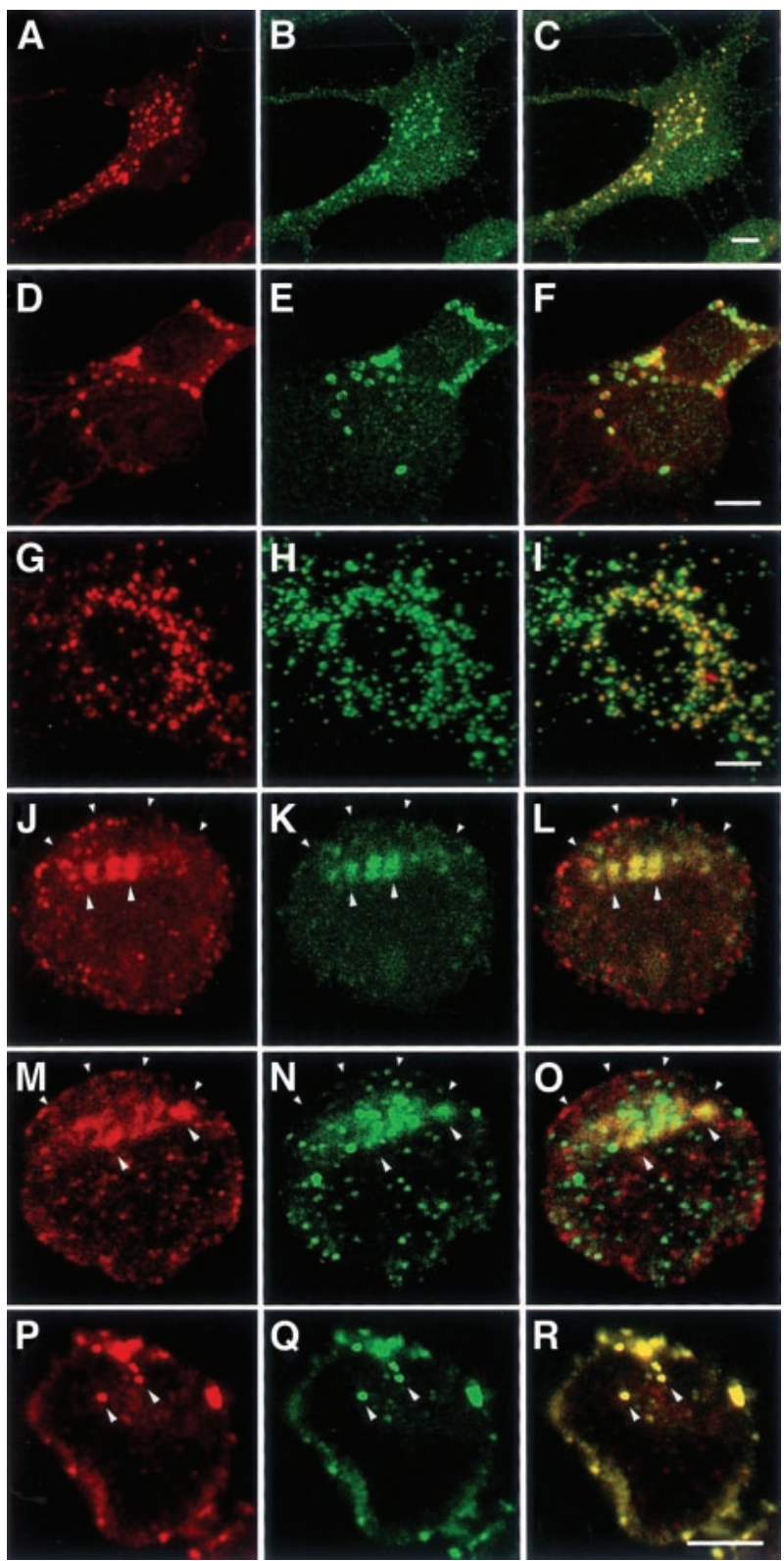

Figure 8. Localization of reggie-1, Thy-1, and fyn in endolysosomes. HRP, taken up by rat astrocytes, is detected by anti-HRP pAB (a). Counterstaining with anti-reggie- $1 \mathrm{mAB}(\mathrm{b})$ reveals colocalization with HRP in cytoplasmic organelles (c). When acidic compartments are detected with the use of the Lysotracker probe (d), labeling partially coincides (f) with anti-reggie-1 stained cytoplasmic organelles (e). Endolysosomes are labeled with anti-limp-2 pAB (h). Anti-reggie-1 mAB labels a subpopulation (i) of the limp-2-positive structures (g). After prolonged exposure of Jurkat cells to cross-linking antibodies, Thy-1 (k) becomes detectable in reggie-1-containing endolysosomes ( $\mathrm{j}$ and $\mathrm{l}$ ). Similarly, fyn (n) is found in reggie-1-positive endolysosomes ( $\mathrm{m}$ and o) after extended incubation with anti-Thy-1 pABs. Accordingly, fyn $(p)$ is colocalized with Thy- 1 ( $q$ and $r$ ). Internalization of cross-linked Thy- 1 is concomitant with a decrease of capped Thy-1, reggie-1, and fyn at the plasma membrane (indicated by small arrowheads). Endolysosomes are marked by the larger arrowheads. Colocalizations are illustrated by superposition of red and green channel images (c, f, i, l, $\mathrm{o}$, and r). Bars, $5 \mu \mathrm{m}$. and anti-Thy-1 and anti-fyn (Figure 8, $\mathrm{q}$ and $\mathrm{r}$ ). This indicates that surface proteins and proteins of the inner face of the plasma membrane, which were associated with reggie in a signaling complex, are both removed from the surface and targeted to endolysosomes for degradation.

\section{DISCUSSION}

Our results characterize reggie- 1 and -2 microscopically and biochemically as constituents of noncaveolar plasma membrane microdomains. LSM and double IG EM analyses of neurons and glial cells demonstrate that reggie-1 and -2 occur in clusters. Moreover, in astrocytes, which are known to posses caveolae (Parton, 1996), reggie-1 and -2 reside outside caveolae and are separate from caveolin-1, which is located within caveolae. In neurons such as PC12 cells and DRGs, which do not exhibit caveolae (Lang et al., 1998), reggie- 1 and -2 represent centers for the accumulation of the GPI-linked surface proteins Thy-1 and F3, especially after being activated by antibody cross-linking, and occur in association with the tyrosine kinase fyn. This suggests that reggie- 1 and -2 are somehow involved in signal transduction, which is consistent with our findings in Jurkat cells. Reggie- 1 and -2 participate in the dynamic accretion into a signal transduction complex (Hooper, 1999) along with fyn kinase, of the activated GPI-linked protein Thy-1, GM1 complexed by CTX, and the T-cell receptor complex. In their participation in signal center formation and their enrichment in DRMs (Bickel et al., 1997; Lang et al., 1998), reggie-1 and -2 exhibit properties of raft-associated proteins. Detection of reggie- 1 and -2 in endolysosomes, the apparent increase of reggie proteins in conjunction with Thy-1 and fyn in endolysosomes of Jurkat cells and the concurrent decrease of these components at the plasma membrane suggests that reggie-1 and -2 , together with fyn and Thy-1, are withdrawn from the surface and become incorporated into endolysosomes. Together, these results are consistent with the view that reggie-1 and -2 participate in the concentration of molecules into microdomains or "raft patches", a process which is thought to be the prerequisite for functioning of distinct signaling cascades (Brückner et al., 2000; Simons and Toomre, 2000). Moreover, our data suggest down-regulation of coclustered proteins by delivery into endolysosomes.

\section{Reggie-1 and -2 Demarcate Plasma membrane Microdomains and Cocluster with Activated GPI- linked Proteins}

Criteria for defining reggie- 1 and -2 as constituents of microdomains are primarily their occurrence together in distinct clusters along the plasma membrane of neurons and astrocytes (revealed by LSM and IG EM), their association with activated GPI-linked proteins and fyn, and their estimated size of $<0.1 \mu \mathrm{m}$. The size of reggie microdomains is conceivably $<0.1 \mu \mathrm{m}$, because primary and secondary antibodies or corresponding gold conjugates, due to their own size $(<30 \mathrm{~nm})$, occupy areas larger than the underlying antigens. More importantly, our results imply that reggie-1 and -2 represent preformed centers for the assembly of activated GPI-linked surface proteins in neurons because reggie microdomains are present before cross-linking of any cell surface molecule. It thus seems possible that reggie 
proteins determine microdomain size in the neurons we analyzed. Evidence from double IG EM shows that activated GPI-linked Thy-1 in PC12 cells is colocalized with both reggie proteins within the $0.1-\mu \mathrm{m}$ size range. In other words, the dimension of mixed gold clusters for the detection of reggie-1 and cross-linked Thy- 1 is apparently no larger than the area occupied by clusters detecting reggie- 1 and -2 . Thus, cross-linking of Thy- 1 in neurons does not increase the size of reggie microdomains. Similar observations were reported on the GPI-anchored protein placental alkaline phosphatase on the apical surface of Madin-Darby canine kidney cells (Verkade et al., 1999).

The microscopic evidence for colocalization of reggie- 1 and -2 , and of reggie with Thy-1 and F3 is supported by results obtained by coimmunoprecipitation. Anti-Thy-1 and anti-F3 coprecipitate reggie-1 and -2 as well as fyn, showing they are associated. Furthermore, anti-fyn precipitates reggie- 1 and -2 in all cells analyzed, and polyclonal and monoclonal reggie-2 ABs coprecipitate reggie-1. Anti-reggie-1 $\mathrm{mAB}$ precipitated reggie-1 but did not coimmunoprecipitate reggie- 2 or fyn, one possible explanation being that the $\mathrm{mAB}$ interferes with the interaction of reggie- 1 with reggie- 2 and fyn. This result, on the other hand, speaks for the specificity of the coimmunoprecipitation procedure. The fact, that fyn coprecipitates with reggie- 1 and -2 in extracts from brain and in all our cultured cells, indicates an association of fyn kinase with reggie proteins. Our finding that F3 is associated with reggie- 1 and -2 and fyn correlates with previous findings demonstrating an association of F3 and fyn in DRMs isolated from mouse cerebellum and maturating oligodendrocytes (Olive et al., 1995; Krämer et al., 1999). Which other GPI-anchored proteins associate with reggie-1 and -2 and fyn remains to be analyzed. Our own unpublished LSM observations suggest that T-cadherin in DRGs coclusters with reggie- 1 and -2 , but the available $A B$ failed to reveal an association in coimmunoprecipitates. Taken together, our results suggests that reggie- 1 and -2 identify one type of raft domain for specific sets of interacting proteins and implies a physical and perhaps functional association of these proteins in signaling centers.

With microscopy, we find that fyn colocalizes to some extent with reggie- 1 and -2 in PC12 cells and DRGs, but not to the same degree that reggie- 1 colocalizes with reggie-2, or Thy-1 and F3 with reggie-1 and -2. One cannot expect such an extensive colocalization of fyn with the other coclustered proteins in neurons because fyn is known to interact with many other proteins. We demonstrated previously (Lang et al., 1998) that the GPI-linked CAM TAG-1, which interacts with fyn (Kunz et al., 1996) and is structurally related to F3, does not copatch with reggie-1 and -2 in DRG neurons, or with F3. This correlates with the current observation that fyn occurs in DRG growth cones inside and outside of reggie patches and implies that microdomains other than those defined by reggie exist. In the case of TAG-1 these other microdomains may include transmembrane CAMs (L1 CAM, NgCAM-related; reviewed in Brümmendorf and Rathjen, 1995).

The presence of coclusters of reggie- 1 and -2 and colocalization with fyn and F3 or Thy-1 in growth cones and filopodia (Figure 2) is consistent with the view that they are perhaps required for axon growth and navigation. The fact that reggie-1 and -2 are up-regulated during axon regener- ation in retinal ganglion cells of fish and in the rat (Schulte et al., 1997; Lang et al., 1998) further indicates that reggie proteins might play a role in axon growth. The presence of coclusters of reggie- 1 and -2 and Thy- 1 in regions of cell-tocell contacts suggests a possible role of these microdomains in cell communication.

\section{Reggie-1 and -2 Are not Associated with Caveolae}

According to previous (Lang et al., 1998) and present results, reggie- 1 and -2 in neurons and astrocytes form plasma membrane microdomains distinct from caveolae. IG EM analysis of astrocytes, which posses caveolae and express caveolin-1 (Parton, 1996; Cameron et al., 1997), demonstrated that gold grains detecting reggie do not reside in caveolae and do not colocalize with gold grains identifying caveolin-1 within caveolae. Nor do reggie proteins coimmunoprecipitate with caveolin-1 in brain and astrocytes. Moreover, quantitative EM analysis of PC12 cells, DRGs and retinal ganglion cells showed the absence of caveolae from these neurons and at the same time revealed the presence of caveolae in astrocytes and DRG-associated satellite cells (Lang et al., 1998). These findings are consistent with the notion that neurons and lymphocytes do not express caveolin-1, and are devoid of caveolae (Fra et al., 1994; Simons and Toomre, 2000), but there are different views on this (Bickel et al., 1997; Galbiati et al., 1998a; Volonté et al., 1999). Vesicular structures in PC12 cells and DRG neurons (Lang et al., 1998) may be interpreted as caveola-like or caveola-related domains (Galbiati et al., 1998a; Simons and Toomre, 2000). Moreover, DRGs, as well as central nervous system neurons, are closely associated with satellite and glial cells, respectively, which express caveolin-1 and exhibit caveolae (Parton, 1996; Cameron et al., 1997; Lang et al., 1998), so that immunoblots (Figure 1) and polymerase chain reaction analysis from such cultures or brain extracts reveal the presence of caveolin-1 (Bickel et al., 1997; Galbiati et al., 1998a), the likely source of which is non-neuronal cells. It is clear that reggie- 1 and -2 become enriched in DRMs (Bickel et al., 1997; Lang et al., 1998; Salzer and Prohaska, 2001) and are thereby possible raft components (Simons and Toomre, 2000). Thus, when DRMs are obtained from mixed cells or even brain, they contain (among others) caveolin and reggie proteins which "float" after sucrose density centrifugation. This, however, does not necessarily mean that proteins assembling in this fraction due to their lipid affinity are colocalized in a given cell (Kurzchalia et al., 1995; Liu et al., 1997; Hooper, 1999); they may not even be expressed by the same cells. Sophisticated subfractionation techniques have allowed to isolate caveolae and lipid rafts separately from the plasma membrane of the same cell (Oh and Schnitzer, 2001). This work supports the notion that caveolae are distinct from rafts and provides evidence for a compartmentalization of signaling molecules in caveolae and lipid rafts rich in GPI-linked proteins. This does not exclude the possibility that specific cell types exhibit specific interactions between proteins being constituents of separate domains in other cells (Baumann et al., 2000).

\section{Reggie-1 and -2 Cocluster with Thy-1, GM1, T-Cell Receptor Complex, and fyn Kinase}

The behavior of reggie- 1 and -2 in activated Jurkat cells is consistent with their potential raft association and their role 
in the formation of signaling centers. Whereas reggie- 1 and -2 , fyn and activated GPI-linked CAMs cocluster in microdomains over the entire extent of neurons and glial cell, raftassociated molecules in T lymphocytes become concentrated in one or more larger patches. This presumably increases signal transduction efficacy (Janes et al., 1999). In fact, the reggie patches in activated Jurkat cells resemble in distribution and size the raft patches of CD 59, lck, and phosphotyrosine illustrated in Harder and Simons (1999). In Jurkat cells, reggie- 1 and -2 exhibit the same dynamic redistribution and showed a substantial degree of colocalization with fyn and activated Thy-1, with GM1 complexed by CTX, the T-cell receptor complex, and phosphotyrosine (Harder and Simons, 1999). This, together with the fact that reggie proteins coprecipitate with fyn, further supports the view that reggie- 1 and -2 are integrated in molecular complexes that serve to increase signal transduction activity.

\section{Reggie-1 and -2 Become Internalized into Endolysosomes}

Our results show that members of the plasma membraneassociated signaling complex, including reggie- 1 and -2 , become internalized into endolysosomes. The intracellular reggie-positive organelles of neurons, glial cells, and Jurkat cells were identified as endolysosomes by incorporation of exogeneously offered HRP, anti-limp-2 immunoreactivity of the membranes surrounding them, and positivity for Lysotracker. In Jurkat cells, the endolysosomes contain Thy-1 and fyn, together with reggie- 1 and -2 , and we observed a decrease of plasma membrane-associated reggie immunoreactivity parallel to an increase of reggie- 1 and -2 immunoreactivity in endolysosomes. This implies a scenario in which interacting raft-associated proteins, previously coclustered in plasma membrane signaling centers, become sequestered in endolysosomes to terminate the activational state of the cell. Stomatin, another DRM protein, was also found to be sequestered together with placental alkaline phosphatase and folate receptor in endosomal/lysosomal compartments (Snyers et al., 1999). We did not detect F3 in reggie-containing endolysosomes of DRG neurons. The efficient recycling machinery in neurons, where GPI-linked proteins can have a remarkably long half-life (Lemansky et al., 1990; Jung et al., 1997; Madore et al., 1999), is just one possible explanation. We cannot exclude the possibility that the delivery of reggie- 1 and -2 to lysosomes serves additional functions apart from those discussed. The cells may overproduce reggie-1 and -2 , naturally or as a result of being increased in culture. In that case, internalization into lysosomes could serve to eliminate excess protein.

\section{Predictions Concerning Structure of Reggie-1 and -2}

The membrane topology of reggie- 1 and -2 is unclear (Bickel et al., 1997; Lang et al., 1998; Volonté et al., 1999). However, if they extend into or through the lipid bilayer, direct physical contact between the GPI-anchored proteins and reggie-1 and -2 might exist. If that were the case, reggie- 1 and -2 could be considered as adaptor proteins (Brown and London, 1998; Harder et al., 1998) between the surface and inner aspect of the plasma membrane. Finally, the degree of evolutionary conservation of reggie-1 and -2 is striking. Both exist in flies (Galbiati et al., 1998b), fish (Schulte et al., 1997; Malaga-Trillo et al., 2001), and warm-blooded vertebrates, including humans (Schroeder et al.,
1994; Bickel et al., 1997; Lang et al., 1998; Salzer and Prohaska, 2001), implying a conserved function.

\section{ACKNOWLEDGMENTS}

We thank Dr. Joachim Hentschel for performing low-temperature embeddings; Dr. Massoud Momayezi for testing some gold conjugates with established standard samples; Claudia Hentschel, Sylvia Kolassa, and Sylvia Hannbeck for excellent technical assistance; and Dr. Martin Bastmeyer for competent help with LSM analysis. This work is supported by grants of the Deutsche Forschungsgemeinschaft to C.A.O.S. and H.P., and the Ministerium für Wissenschaft und Kunst, Baden-Württenberg (MWK), Bundesministerium für Bildung, Wissenschaft, Forschung and Technologie, and Fond s der Chemischen Industrie (FCI).

\section{REFERENCES}

Baumann, A., Ribon, V., Kanzaki, M., Thurmond, D.C., Mora, S., Shigematsu, S., Bickel, P.E., Pessin, J.E., and Saltiel, A.R. (2000). CAP defines a second signaling pathway required for insulin-stimulated glucose transport. Nature 407, 202-207.

Bickel, P.E., Scherer, P.E., Schnitzer, J.E., Oh, P.M., Lisanti, P., and Lodish, H.F. (1997). Flotillin and epidermal surface antigen define a new family of caveolae-associated integral membrane proteins. J. Biol. Chem. 272, 19793-19802.

Brown, D. (1993). The tyrosine kinase connection: how GPI-anchored proteins activate T-cells. Curr. Opin. Immunol. 5, 349-354.

Brown, D.A., and London, E. (1998). Functions of lipid rafts in biological membranes. Annu. Rev. Cel. Dev. Biol. 14, 111-136.

Brückner, K., Labrador, J.P., Scheiffele, P., Herb, A., Seeburg, P.H., and Klein, R. (2000). EphrinB ligands recruit GRIP family PDZ adaptor proteins into raft membrane microdomains. Neuron 22, 511-524.

Brümmendorf, T., and Rathjen, F.G. Eds. (1995). Cell adhesion molecules I: immunoglobulin superfamily. In: Protein Profiles, London, England: Academic Press.

Cameron, P.L., Ruffin, J.W., Bollag, R., Rasmussen, H., and Cameron, R.S. (1997). Identification of caveolin and caveolin-related proteins in the brain. J. Neurosci. 15, 9520-9535.

Fra, A.M., Williamson, E., Simons, K., and Parton, R.G. (1994). Detergent-insoluble glycolipid microdomains in lymphocytes in the absence of caveolae. J. Biol. Chem. 269, 30745-30748.

Friedrichson, T., and Kurzchalia, V. (1998). Microdomains of GPIanchored proteins in living cells revealed by crosslinking. Nature 394, 802-805.

Galbiati, F., et al. (1998a). Expression of caveolin-1 and -2 in differentiating PC12 cells and dorsal root ganglion neurons: caveolin-2 is upregulated in response to cell injury. Proc. Nat. Acad. Sci. USA, 95, 10257-10262.

Galbiati, F., Volonté, D., Goltz, J.S., Steele, Z., Sen, J., Jurcsak, J., Stein, D., Stevens, L., and Lisanti, P.M. (1998b). Identification, sequence and developmental expression of invertebrate flotillins from Drosophila melanogaster. Gene 210, 229-237.

Gorodinsky, A., and Harris, D.A. (1995). Glycolipid-anchored proteins in neuroblastoma cells form detergent-resistant complexes without caveolin. J. Cell Biol. 129, 619-627.

Harder, T., Scheiffele, P., Verkade, P., and Simons, K. (1998). Lipid domain structure of the plasma membrane revealed by patching of membrane components. J. Cell Biol. 141, 929-942.

Harder, T., and Simons, K. (1997). Caveolae, DIGS, and the dynamics of sphingolipid-cholesterol microdomains. Curr. Opin. Cell Biol. 9, $534-542$. 
Harder, T., and Simons, K. (1999). Clusters of glycolipid and glcosylphosphatidylinositol-anchored proteins in lymphoid cells: accumulation of actin regulated by local tyrosine phosphorylation. Eur. J. Immunol. 29, 556-562.

Hooper, N.M. (1999). Detergent-insoluble glycosphingolipid/cholesterol-rich membrane domains, lipid rafts and caveolae. Mol. Membr. Biol. 16, 145-156.

Ilangumaran, S., Arni, S., Echten-Deckert, G.V., Borisch, B., and Hoessli, D.C. (1999). Microdomain-dependent regulation of Lck and Fyn protein-tyrosine kinases in $\mathrm{T}$ lymphocyte plasma membranes. Mol. Biol. Cell 10, 891-905.

Janes, P.W., Ley, S.C., and Magee, A.I. (1999). Aggregation of lipid rafts accompanies signaling via the $\mathrm{T}$ cell antigen receptor. J. Cell Biol. 147, 447-461.

Jung, M., Petrausch, B., and Stuermer, C.A.O. (1997). Axon-regenerating ganglion cells in adult rats synthesize the cell adhesion molecule L1 but not TAG-1 or SC-1. Mol. Cell. Neurosci. 9, 116-131.

Krämer, E.-M., Klein, C., Koch, T., Boytin, M., and Trotter, J. (1999). Compartmentation of Fyn kinase with glycosylphosphatitylinositolanchored molecules in oligodendrocytes facilitates kinase activation during myelination. J. Biol. Chem. 274, 29042-29049.

Krämer, E.-M., Koch, T., Niehaus, A., and Trotter, J. (1997). Oligodendrocytes direct glycosyl phosphatidylinositol-anchored proteins to the myelin sheath in glycosphingolipid-rich complexes. J. Biol. Chem. 272, 8937-8945.

Kunz, S., Ziegler, U., Kunz, B., and Sonderegger, P. (1996). Intracellular signaling is changed after clustering of the neural cell adhesion molecules axonin- 1 and $\mathrm{NgCAM}$ during neurite fasciculation. J. Cell Biol. 135, 253-267.

Kurzchalia, T.V., Hartmann, E., and Dupree, P. (1995). Guilt by insolubility-Does a protein's detergent insolubility reflect a coveolar location? Trends Cell Biol. 5, 187-189.

Lang, D.M., Hille, M.G., Schwab, M.E., and Stuermer, C.A.O. (1996). Modulation of the inhibitory substrate properties of oligodendrocytes by platelet-derived growth factor. J. Neurosci. 16, 5741-5748.

Lang, D.M., Lommel, S., Jung, M., Ankerhold, R., Petrausch, B., Laessing, U., Wiechers, M.F., Plattner, H., and Stuermer, C.A.O. (1998). Identification of reggie-1 and reggie-2 as plasmamembraneassociated proteins which cocluster with activated GPI-anchored cell adhesion molecules in non-caveolar micropatches in neurons. J. Neurobiol. 37, 502-523.

Lemansky, P., Fatemi, S.H., Gorican, B., Possero, R., and Tartakoff, A.M. (1990). Dynamics and longevity of the glycolipid-anchored membrane protein Thy-1. J. Cell Biol. 110, 1525-1531.

Lisanti, M.P., Scherer, P.E., Tang, T., and Sargiacomo, M. (1994). Caveolae, caveolin and caveolin rich membrane domains: a signaling hypothesis. Trends Cell Biol. 4, 231-235.

Liu, J., Oh, P., Horner, T., Rogers, R.A., and Schnitzer, J.E. (1997). Organized endothelial cell surface signal transduction in caveolae distinct from glycosylphosphatidylinositol-anchored protein microdomain. J. Biol. Chem. 272, 7211-7222.

Madore, N., Smith, K.L., Graham, C.H., Jen, A., Brady, K., Hall, S., and Morris, R. (1999). Functionally different GPI proteins are organized in different domains on the neuronal surface. EMBO J. 18, 6917-6926.

Mains, R.E., and Patterson, P.H. (1973). Primary cultures of dissociated sympathetic neurons. 1. Establishment of long-term growth in culture and studies of differentiated properties. J. Cell Biol. 59, 329-345.

Malaga-Trillo, E., Laessing, U., Lang, D.M., Meyer, A., and Stuermer, C.A.O. (2001) Evolution of duplicated reggie genes in zebrafish and goldfish. J. Mol. Evol. (in press).
Momayezi, M., Kissmehl, R., and Plattner, H. (2000). Quantitative immunogold localization of protein phosphatase $2 \mathrm{~B}$ (calcineurin) in Paramecium cells. J. Histochem. Cytochem. 48, 1269-1281.

Nagorni, M., and Hell, S.W. (1998). 4pi-confocal microscopy provides three-dimensional images of the microtubule network with 100- to 150-nm resolution. J. Struct. Biol. 123, 236-247.

Oh, P., and Schnitzer, J.E. (2001). Segregation of heterotrimeric G proteins in cell surface microdomains. Gq binds caveolin to concentrate in caveolae, whereas Gi and Gs target to lipid rafts by default. Mol. Biol. Cell 12, 685-698.

Olive, S., Dubois, C., Schachner, M., and Rougon, G. (1995). Caveolins, a family of scaffolding proteins for organizing preassembled signaling complexes at the plasma membrane. J. Neurochem. 65, 2307-2317.

Parton, R.G. (1996). Caveolae and caveolins. Curr. Opin. Cell Biol. 8, 542-548.

Salzer, U., and Prohaska, R. (2001). Stomatin, flotillin-1 and flotillin-2 are major intergral proteins of erythrocytes lipid rafts. Blood 97, 1141-1143.

Sambrook, J., Fritsch, E.F., and Maniatis, T. (1989). Molecular Cloning: A Laboratory Manual, Cold Spring Harbor, NY: Cold Spring Harbor Laboratory Press.

Schnitzer, J.E., McIntosh, D.P., Dvorak, A.M., Liu, J., and Oh, P. (1995). Separation of caveolae from associated microdomains of GPI-anchored proteins. Science 269, 1435-1439.

Schroeder, W., Stewart-Galetka, S., Parry, D.A., Goldsmith, D., and Duvic, M.L. (1994). Cloning and characterization of a novel epidermal cell surface antigen (ESA). J. Biol. Chem. 269, 19983-19991.

Schulte, T., Paschke, K.A., Laessing, U., Lottspeich, F., and Stuermer, C.A.O. (1997). Reggie-1 and reggie-2, two cell surface proteins expressed by retinal ganglion cells during axon regeneration. Development 124, 577-587.

Simons, K., and Ikonen, E. (1997). Functional rafts in cell membranes. Nature 387, 569-572.

Simons, K., and Toomre, D. (2000). Lipid rafts, and signal transduction. Nature Reviews 11, 31-39.

Snyers, L., Umlauf, E., and Prohaska, R. (1999). Association of stomatin with lipid-protein complexes in the plasma membrane and the endocytic compartment. Eur. J. Cell Biol. 78, 802-812.

Thomas, P.M., and Samelson, L.E. (1992). The glycophosphatidylinositol-anchored Thy-1 molecule interacts with the p60fyn protein tyrosine kinase in T cells. J. Biol. Chem. 267, 12317-12322.

Varma, R., and Mayor, S. (1998). GPI-anchored proteins are organized in submicron domains at the cell surface. Nature 394, 798801

Vega, M.A., Segui-Real, B., Garcia, J.A., Cales, C., Rodrigues, M.F., Vanderkerckhove, J., and Sandoval, V.I. (1991). Cloning, sequencing, and expression of a cDNA encoding rat LIMP II, a novel $74 \mathrm{kDa}$ lysosomal membrane protein related to the surface adhesion protein CD36. J. Biol. Chem. 266, 16818-16824.

Verkade, P., Harder, T., Lafont, F., and Simons, K. (1999). Induction of caveolae in the apical plasma membrane of Madin-Darby Canine Kidney cells. J. Cell Biol. 148, 727-739.

Volonté, D., Galbiati, F., Li, S. Nishiyama, K., Okamoto T., and Lisanti, M.P. (1999). Flotillins/cavatellins are differentially expressed in cells and tissues and form a hetero-oligomeric complex with caveolins in vivo. J. Biol. Chem. 274, 12702-12709.

Weiss, A. (1993). T cell antigen receptor signal transduction: a table of tails and cytoplasmic protein-tyrosine kinases. Cell 73, 209-212. 